\title{
Characteristics of the TOVS Pathfinder Path-B Dataset
}

\author{
Noëlle A. Scott, ${ }^{*}$ Alain Chédin, ${ }^{*}$ Raymond Armante, ${ }^{*}$ \\ Jennifer Francis, ${ }^{+}$Claudia Stubenrauch, ${ }^{*}$ Jean-Pierre Chaboureau,, ,@ \\ Frederic Chevallier, ${ }^{\#, \&}$ Chantal Claud, ${ }^{*}$ and Frédérique Cheruy*
}

\begin{abstract}
From 1979 to present, sensors aboard the NOAA series of polar meteorological satellites have provided continuous measurements of the earth's surface and atmosphere. One of these sensors, the TIROS-N Operational Vertical Sounder (TOVS), observes earth-emitted radiation in 27 wavelength bands within the infrared and microwave portions of the spectrum, thereby creating a valuable resource for studying the climate of our planet. The NOAA-NASA Pathfinder program was conceived to make these data more readily accessible to the community in the form of processed geophysical variables. The Atmospheric Radiation Analysis group at the Laboratoire de Méteorologie Dynamique of the Centre National de la Recherche Scientifique of France was selected to process TOVS data into climate products (PathB). The Improved Initialization Inversion (3I) retrieval algorithm is used to compute these products from the satelliteobserved radiances. The processing technique ensures internal coherence and minimizes both observational and computational biases. Products are at a $1^{\circ} \times 1^{\circ}$ latitude-longitude grid and include atmospheric temperature profiles (up to $10 \mathrm{hPa}$ ); total precipitable water vapor and content above four levels up to $300 \mathrm{hPa}$; surface skin temperature; and cloud properties (amount, type, and cloud-top pressure and temperature). The information is archived as 1-day, 5-day, and monthly means on the entire globe; A.M. and P.M. products for each satellite are stored separately. Eight years have been processed to date, and processing continues at the rate of approximately two satellite-months per day of computer time. Quality assessment studies are presented. They consist of comparisons to conventional meteorological data and to other remote sensing datasets.
\end{abstract}

\section{Introduction}

One of the major challenges of the forthcoming decade is to analyze in every detail the impact of modi-

\footnotetext{
*Laboratoire de Météorologie Dynamique du CNRS, Palaiseau, France.

+Institute of Marine and Coastal Sciences, Rutgers, The State University of New Jersey, New Brunswick, New Jersey.

"Laboratoire de Météorologie Dynamique, Ecole Polytechnique, Palaiseau, France.

${ }^{\circledR}$ Current affiliation: Laboratoire d'Aérologie, Observatoire MidiPyrénées, Toulouse, France.

${ }^{\&}$ Current affiliation: ECMWF, Shinfield Park, Berkshire, United Kingdom.

Corresponding author address: Noëlle A. Scott, Ecole Polytechnique, Laboratoire de Météorologie Dynamique, 91128 Palaiseau Cedex, France.

E-mail: nas@jungle.polytechnique.fr

In final form 2 June 1999.

(C)1999 American Meteorological Society
}

fications to the atmospheric composition that are likely to have an effect on the earth's climate. To respond to this challenge, it is essential both to understand the mechanisms that regulate the present climate and are capable of changing it and to accurately characterize the natural variability of any atmospheric or surface variable.

The basic tool for observing the planet on a global and continuous basis is the operational and/or research satellite, in either a polar or geostationary orbit. Various components of the earth system can be observed with instruments that measure emitted and reflected radiances in either high or low spatial or spectral resolutions in a large variety of wavelengths (e.g., microwave, infrared, visible, and beyond).

The National Oceanic and Atmospheric Administration (NOAA) series of operational polar satellites carries onboard instruments (multifrequency radiometers) called vertical sounders. Data from these instruments (see section 2), when interpreted by appropriate 
methods, provide four-dimensional "photos" of the thermodynamic state of the atmosphere. Latitude, longitude, altitude, and time are the dimensions by which the observed variables are described. These variables include thermal structure, moisture, cloud cover, radiation flux, surface states (temperature, type), and ozone. This ability to perform soundings of the atmosphere is based on the characteristics of absorption, emission, and diffusion of molecules (such as water vapor, carbon dioxide, ozone, methane, etc.), and particles (ice, liquid water, aerosols, etc.) encountered in the atmosphere. To make these data and products derived from them more accessible to the scientific community, NOAA and the National Aeronautics and Space Administration (NASA) initiated the Pathfinder Program. The primary goal of this project is to assemble and distribute raw satellite data to selected researchers for processing the relatively long records (nearly 20 years) into useful geophysical quantities.

The processing and analysis of observations from space for climate study involves working with a wide variety of disciplines, such as quantum molecular spectroscopy, atmospheric radiative transfer (direct and inverse), estimation theory (bayesian inference, pattern recognition, artificial neural networks), and time series analysis. To set up software for such a variety of methods also involves tens of thousands of instructions and requires large storage capacities. The Atmospheric Radiation Analysis (ARA) group at Laboratoire de Météorologie Dynamique (LMD) has set as a goal to translate this range of knowledge either by using a combination of spectroscopic or climatic databases, and algorithms, such as the Automatized Atmospheric Absorption Atlas (4A) radiative transfer model (Scott and Chédin 1981) or the Improved Initialization Inversion (3I) system for interpretation of space-based observations of vertical sounders. This system of algorithms is described in section 3. Working within the framework of several major climate research programs set up under the auspices of the World Climate Research Program (WCRP), NASA, NOAA, or the European Community Commission (ECC), the LMD has participated in both partial [the Global Energy and Water Cycle Experiment (GEWEX) of the WCRP or the ECC's environmental programs] and total (the NOAA-NASA Pathfinder Program) reanalyses of these satellite data. As a member of the Pathfinder Program, we have processed TOVS data into the so-called Path-B dataset.

The main goals of our participation in Pathfinder are
- to generate quality-controlled climatologies of relevant variables such as three-dimensional distributions of temperature and water vapor, the characteristics of clouds (top pressure and temperature, effective amount, and type) and of surfaces (temperature, presence of snow, sea ice, desert) and to analyze their variations and trends; and

- to contribute to the improvement of numerical models of climate simulation through a better description of certain complex processes which, at the present time, tend to be parameterized rather crudely.

So far, within the framework of the NOAA-NASA Pathfinder Program (Path-B), the processing of several years of such observations has been performed at LMD. Details of the Path-B data are presented in section 4 . The results presented in this paper are from the NOAA-10 and NOAA-12 satellites for a period of time extending from January 1987 to June 1995 . At present, we are able to process 2 months of satellite data per computing day.

Quality assessment studies have been conducted within the framework of international intercomparison projects for the inverse as well as for the forward problem. Among them are the International TOVS Study Conferences (ITSC), the Intercomparison of Transmittance and Radiance Algorithms (ITRA), the International Comparison of Radiation codes in Climate Models (ICRCCM), the International Satellite Cloud Climatology Project (ISCCP), etc. The monitoring of observational and computational biases, as well as the quality control developed for the Path-B products, are presented in section 5 .

The validation of Path-B products involves comparing satellite-retrieved variables to conventional data and to other remote sensing products. Results are presented in section 6 .

Numerous applications of the Path-B dataset are under way and envisioned. Some of these studies include examining the relationship between vertical dynamics, sea surface temperature, and the vertical distribution of water vapor (Chaboureau et al. 1998b); investigating the seasonal, interannual, and zonal temperature variability of the tropical stratosphere between 1987 and 1991 (Claud et al. 1999); improving our understanding of cloud radiative effects by combining 3I and ISCCP cloud parameters (Stubenrauch et al. 1999); and studying the role of natural and internal forcings in the observed variability (Aires et al. 1999, manuscript submitted to J. Geophys. Res.). 


\section{The input dataset}

The overall mission of the TIROS-N Operational Vertical Sounder (TOVS) instruments aboard the NOAA Polar Orbiting Environmental Satellites (POES) is to provide continuous, global measurements of atmospheric temperature and moisture profiles.

The TOVS consists of three passive vertical sounding instruments (Smith et al. 1979): the High resolution Infrared Radiation Sounder (HIRS-2), a radiometer with 19 channels in the infrared band and one in the visible band; the Microwave Sounding Unit (MSU), a microwave radiometer with four channels in the vicinity of $55 \mathrm{GHz}$; and the Stratospheric Sounding Unit (SSU), a pressure-modulated infrared radiometer with three channels near $15 \mu \mathrm{m}$. To retrieve atmospheric temperature and humidity fields with the 3I algorithm, only HIRS and MSU data are used. Scan widths are approximately $2200 \mathrm{~km}$ wide, providing global coverage every $12 \mathrm{~h}$.

HIRS-2 measures atmospheric and/or surface emission in seven $15.0-\mu \mathrm{m} \mathrm{CO}_{2}$ channels, five $4.3-\mu \mathrm{m}$ $\mathrm{CO}_{2}$ channels, one 11.0- $\mu \mathrm{m}$ window channel, and three 6.7- $\mu \mathrm{m} \mathrm{H}_{2} \mathrm{O}$ channels. Surface and $\mathrm{O}_{3}$ emission is measured in one 9.6- $\mu \mathrm{m}$ window channel, surface emission and reflected solar radiation in two $3.7-\mu \mathrm{m}$ window channels, and reflected solar radiation in one visible channel. Nadir resolution is approximately $17 \mathrm{~km}$.

The MSU measures atmospheric emission in three $55-\mathrm{GHz} \mathrm{O}_{2}$ channels and surface and atmospheric emission in one $55-\mathrm{GHz}$ window channel. Nadir resolution is approximately $110 \mathrm{~km}$.

The NOAA-NASA Pathfinder Program has, to date, made available to LMD a vast archive of level 1-B satellite data as shown in Table 1.

\section{Retrieval methodology: The Improved Initialization Inversion (3I) system}

Spaceborne radiometers observe spectral radiances that are emitted or backscattered by the atmosphere into the direction of the satellite. For the derivation of atmospheric and surface products from the radiance spectrum, retrieval algorithms are required that comprise all steps needed to "translate" instrument data into the final products. These steps include the simulation of observed radiances and brightness temperatures with forward radiative transfer models, the ingestion of auxiliary databases, the inversion process to obtain geophysical products, and the generation of gridded products.

The 3I method was developed at LMD for this purpose and has been extensively discussed in the literature. For its complete description, the reader is referred to Chédin and Scott $(1984,1985)$, Chédin et al. (1985, 1989, 1994), and Chédin (1988). An updated overview of the method used for reanalyzing of the TOVS observations for the Path-B dataset is given below.

The 3I inversion algorithm is a direct, noniterative, physical-statistical method. It uses data from the HIRS (infrared) and MSU (microwave) radiometers.

\section{a. Calibration and collocation}

Starting from the level 1B data, HIRS and MSU observations are calibrated using coefficients provided by NOAA following the procedures set forth in the NOAA Polar Orbiter User's Guides.

The spatial resolution of 3I retrievals is a compromise between the spatial resolutions of the HIRS and MSU sounders. A $3 \times 2$ (at the edges of an orbit), or 3 $\times 3$, or $3 \times 4$ (at nadir) array of HIRS spots is grouped together and collocated with the nearest MSU spot(s). Such "boxes" represent a surface of nearly 100 $\times 100 \mathrm{~km}^{2}$, and retrievals are performed for each array. The same kind of mapping is applied to the topography dataset, which describes the terrain elevation and the percentage of water covering the surface.

\section{b. Cloud detection}

The 3I inversion scheme requires information about the presence of clouds within the field-of-view. Owing to their relative insensitivity to clouds, microwave channels play a major role in their detection. The box is identified as cloud-free, partially cloudy, or

TABLE 1. TOVS Pathfinder level 1-B data archive at LMD.

\begin{tabular}{ll}
\hline \hline Satellite & Archive date range (at LMD) \\
\hline TIROS-N & $11 / 1978$ to $01 / 1981$ \\
\hline NOAA-6 & $07 / 1979$ to $03 / 1983$ and $01 / 1986$ to $09 / 1986$ \\
\hline NOAA-7 & $07 / 1981$ to $01 / 1985$ \\
\hline NOAA-9 & $01 / 1986$ to $12 / 1986$ \\
\hline NOAA -10 & $01 / 1987$ to $09 / 1991$ \\
\hline NOAA -11 & $01 / 1989$ to $09 / 1992$ and $02 / 1993$ to $12 / 1994$ \\
\hline NOAA -12 & $01 / 1992$ to $12 / 1994$ \\
\hline
\end{tabular}


overcast depending on the outcome of a series of seven (night)/eight (day) threshold and coherence tests based on the work by Wahiche et al. (1986), and improved by Stubenrauch et al. (1998a), applied to each HIRS spot in the box. Additional tests aim at unambiguously distinguishing between clouds and special surface conditions (e.g., warm surfaces, snow, sea ice, etc.).

Cloud identification in the polar regions, where clouds are sometimes warmer than the surface, has been improved with respect to the original version (Francis 1994). Clouds over snow and sea are identified by a difference between the 3.7- and $11-\mu \mathrm{m}$ brightness temperatures. The cloud detection is performed differently over sea ice, water, and land.

\section{c. Inversion}

Provided the observed brightness temperatures correspond to clear areas or have been properly "cleared," the 3I procedure follows two principal steps (see Fig. 1).

1) Retrieval of the initial guess solution: the observed clear column radiances are first used to retrieve the "best" initial guess solution. The procedure makes uses of the Thermodynamic Initial Guess Retrieval (TIGR) dataset. The selected set of observed radiances (or equivalent brightness temperatures) and corresponding a priori information on the situation observed are compared with each equivalent set archived in TIGR and the "closest" is retained.

2) The basis for the retrieval of the "exact" solution is a maximum probability estimation procedure aimed at minimizing the differences between the brightness temperatures associated with the initial guess and the observed ones. Use is made of the Jacobian associated with the retrieved initial guess in the TIGR dataset.

\section{d. The Thermodynamic Initial Guess Retrieval (TIGR) dataset}

This (frozen) library of atmospheres, the TIGR dataset, consists of about 1800 situations (recently extended to about 2300 situations for a better representation of the tropical regions; see below) selected by statistical methods out of 150000 radiosonde reports. Clear sky transmittances, radiances, and weighting functions for all TOVS sounding channels are precomputed for each situation in TIGR by the Automatized Atmospheric Absorption Atlas (4A) fast line-byline model of Scott and Chédin (1981). Calculations are performed for 10 viewing angles between $0^{\circ}$ (na-

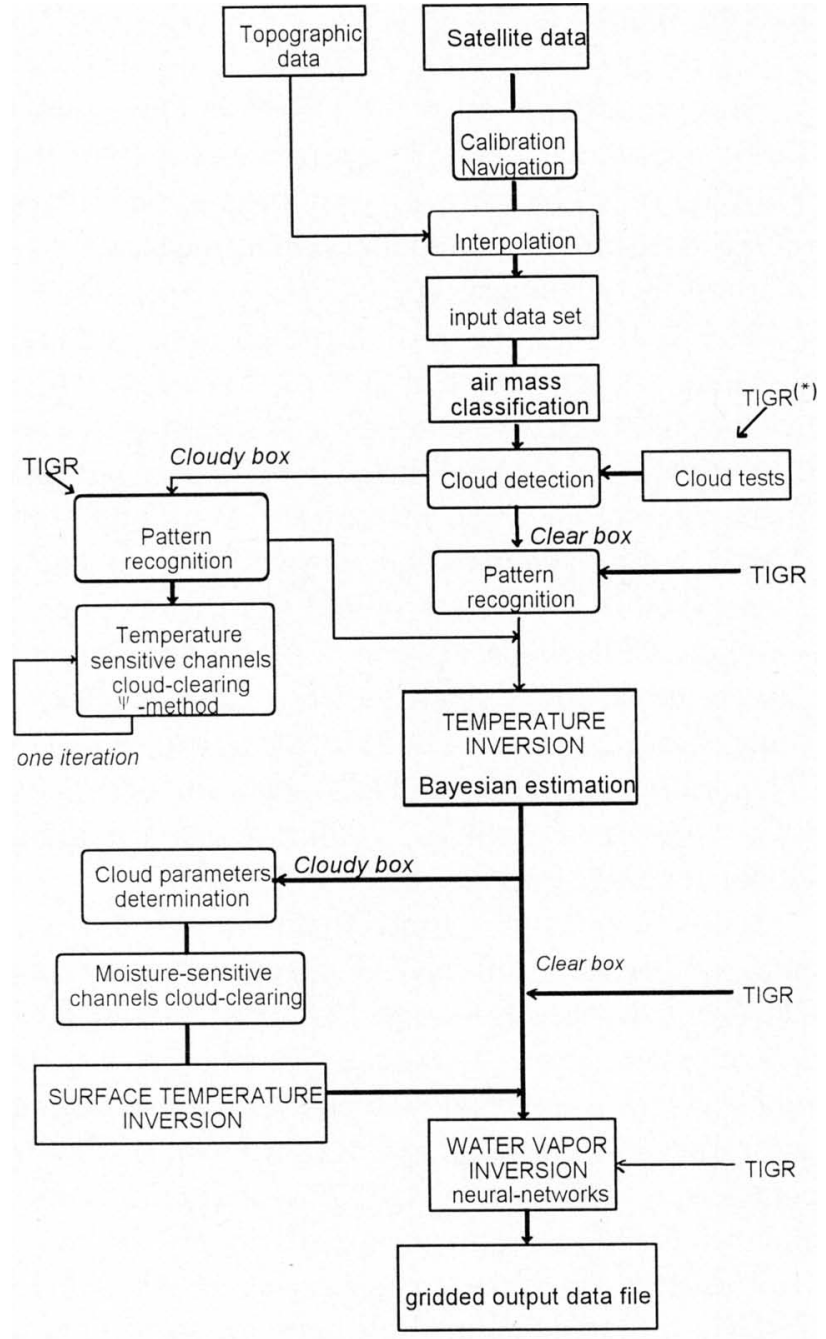

$\left.{ }^{*}\right)$ Thermodynamic Initial Guess Retrieval

FIG. 1. The 3I processing flow chart.

dir) and $60^{\circ}$ (the maximum value for angular scanning), for 19 values of surface pressure (up to about $500 \mathrm{hPa}$ for elevated terrain), and for two surface types: land and sea. These results are also stored within the TIGR dataset. It is worth pointing out that TIGR is not sensitive to the relative quality of the radio soundings sampled in it but only to their representativeness and plausibility. In fact, it is sensitive to the quality of the relationship between thermodynamic quantities and radiative quantities. For that reason, great attention has been paid to the validation of the 4A model.

The situations in TIGR have been stratified by a hierarchical ascending classification into five airmass classes, depending on their virtual temperature profiles (Achard 1991; Chédin et al. 1994). Given an observation, that is, the HIRS-2 and MSU brightness tempera- 
tures, a distance between the observation and the gravity center of each class in the TIGR dataset, using a set of four TOVS channels, is calculated in order to assign one of these airmass types (hereafter called tropical, midlatitude 1 and 2, and polar 1 and 2) to this observation.

\section{e. Selection of the first guess solution of the inversion process}

Identification of the "closest situation" is performed through a pattern recognition approach using the observed brightness temperatures to describe the state of the underlying atmosphere. In case of cloudy situations, the initial guess is obtained after a two-step procedure, one of which is the cloud clearing process (Chédin and Scott 1984; Chédin et al. 1985). Clear cases involve only step 2 .

\section{1) Step 1: Cloud Clearing OF TEMPERATURE- SENSITIVE CHANNELS}

The earth is approximately $60 \%$ cloud covered on average, thus a method is needed to remove the effects of clouds on the radiances. Because the quality of the retrieved products is fundamentally determined by the quality of the cloud clearing, this step is of paramount importance. The cloud clearing algorithm is an integral part of the whole retrieval system as it takes advantage of coincident knowledge of other parameters. To derive the brightness temperatures that would have been observed under clear sky conditions, 3I relies upon the coupling between MSU and HIRS channels through the so-called Psi method (Chédin et al. 1985). Interchannel regression techniques are applied-based upon the TIGR dataset-where the infrared channels are the predictands and the microwave and noncontaminated infrared channels are the predictors. See Chaboureau (1997) for more details.

\section{2) Step 2: Selection of the First Guess}

The proximity recognition for the first guess search is then performed by comparing the observed or cloud cleared radiances with the calculated radiances corresponding to each archived atmospheric situation belonging to the previously determined airmass type. The mean of the closest situations is taken as the initial solution.

\section{f. Temperature profile retrieval: A Bayesian approach}

The principal difficulty in inverting the radiative transfer equation for retrieving geophysical parameters (i.e., minimizing the differences between the observation and the initial solution) is related to the fact that standard mathematical approaches do not yield unique and/or stable solutions. Colinearities among the variables, inherent to the physical aspect of this problem, render "traditional" estimates (e.g., ordinary least squares) less accurate and less useful than usually expected. Adding prior information to the data directly leads to Bayesian statistics, indicating that estimates should be modified according to knowledge that may be available prior to the gathering of the data. In our case, this a priori knowledge is extracted from the TIGR dataset through differential temperature covariance matrices, one for each condition of observation: surface pressure, viewing angle, land/sea flag, clear/ cloudy flag, airmass type, etc. (Chédin et al. 1985). These matrices are computed by applying the proximity recognition algorithm to all the TIGR subsets, assuming they are of either clear or cloudy situations.

\section{g. Cloud parameters (top pressure, effective amount, and type)}

After the estimation of the temperature profile, cloud properties are determined from the radiances averaged over all pixels declared cloudy within each $100 \mathrm{~km} \times 100 \mathrm{~km}$ box, assuming that they are covered by a single, homogeneous cloud layer. The average cloud-top pressure and the effective cloud amount are obtained by a weighted- $\chi^{2}$ method using four $15-\mu \mathrm{m}$ $\mathrm{CO}_{2}$-band radiances (HIRS channels 4 to 7 ) and the $11-\mu \mathrm{m}$ atmospheric window radiance. The weights are channel- and cloud-level dependent (Stubenrauch et al. 1999b). The empirical weights reflect the usefulness of a spectral channel at a cloud level for the determination of the effective cloud amount. This new method is much less sensitive to errors in the temperature profile than the original 3I method (see Wahiche et al. 1986), which, like other currently used methods, involved a denominator getting near zero under certain conditions (low clouds). The cloud-top pressure is transformed into cloud-top temperature using the 3Iretrieved atmospheric temperature profiles. A cloud cover fraction is also determined as the fraction of cloudy HIRS pixels in each grid box.

The 3I cloud parameters have been carefully evaluated on a global scale (Stubenrauch et al. 1999a, 1999c) by comparison with time-space collocated, recently reprocessed ISCCP cloud parameters (Rossow et al. 1996), which are being intensively checked by many ongoing studies. These comparisons reveal considerable improvement in the 3 I cloud pa- 
rameters. The remaining disagreements with ISCCP can be explained by grid heterogeneities (vertical and horizontal) or by differences in cloud detection (Stubenrauch et al. 1999a, 1999c).

\section{h. Cloud clearing of moisture-temperature sensitive channels}

The cloud characteristics are used to cloud clear infrared channels (i.e., HIRS channels 7, 8, 10, 11, 12, $13,18,19)$ that are sensitive to both moisture and temperature. Use is made of the well-known formula (Smith 1967) that expresses the observed radiance as a function of the equivalent clear radiance (same situation in the absence of cloud) and the cloudy radiance (full coverage of a black cloud at the correct top pressure). This is done only when the effective cloud amount is less than $60 \%$.

\section{i. Surface temperature}

Radiances in spectral windows carry information about the temperature of the earth's surface. For the derivation of surface temperature, contribution to the observed radiances from water vapor, surface emissivity, clouds, etc., have to be accounted for. In the medium infrared, the surface emissivity has a value close to 1 , slightly smaller over land than over sea. It is somewhat smaller in the near infrared $(3.7-\mu \mathrm{m}$ windows), particularly over land, and it is affected by the "reststrahlen" (decrease of the emissivity due to $\mathrm{SiO}_{2}$ radiative properties) effect over bare soils and deserts near $8 \mu \mathrm{m}$ (channel 10).

The surface temperature retrieval algorithm depends on the clear/cloudy flag. For clear or partially clear boxes, the surface temperature is obtained through regressions whose coefficients are obtained from TIGR (one set of coefficients per observing condition). Shortwave window channels are not used during the day. Channel 10 is not used over desert areas [detected by a threshold test on the difference between the brightness temperatures of channels 8 (near $11 \mu \mathrm{m}$ ), and 10]. For cloudy boxes, a ridge-type (regularized least squares) estimator is used based on the same cloud cleared channels. No attempt is made when the effective cloud amount is larger than $60 \%$. Improvements made to the algorithm for icecovered, very cold surfaces (Francis 1994) were recently incorporated.

Although not the best instrument for retrieving surface temperature, the advantage of TOVS is that fields are coherent with the other variables describing the atmospheric state (temperature and moisture pro- files, clouds, etc.). Moreover, the accuracy of 3I sea surface temperature is satisfactory (see below).

\section{j. Microwave emissivity and sea ice detection}

The microwave emissivity is derived from the MSU channel 1. Emissivity is particularly useful for identifying sea ice in a field of view. Sea ice is detected by a high microwave surface emissivity ( $>76 \%$ ) associated with an 11- $\mu \mathrm{m}$ brightness temperature less than $268 \mathrm{~K}$. Open sea is defined by a microwave surface emissivity less than $65 \%$.

\section{k. Moisture profile retrieval: A nonlinear neural network estimate}

It is well known that the main difficulties in retrieving water vapor from TOVS arise from the coarse vertical resolution of the water vapor-sensitive channels (mainly channels 8, 10, 11, 12), limited information near the surface, contamination by surface conditions, and the removal of cloud effects. Moreover, the inversion process is highly nonlinear.

Over the last decade, neural networks have proven their ability to handle nonlinear problems and have increasingly been used in forward or inverse radiative transfer problems related to satellite-borne observations (Escobar-Munoz et al. 1993; Cheruy et al. 1996; Rieu et al. 1996).

The original 3I algorithm used a ridge-type linearized estimation method (Chédin et al. 1985). Recently, a new algorithm has been derived that consists of a multilayered perceptron (Rumelhart et al. 1986). To retrieve the vertical distribution of humidity, brightness temperatures of the four channels most sensitive to water vapor absorption (HIRS 8, 10, 11, and 12), are combined with six channels at $15 \mu \mathrm{m}$ (from HIRS 2 to 7) to introduce information about the vertical structure of temperature. Outputs from the network are the precipitable water contents for five standard layers (100-300, 300-500, 500-700, 700-850, and 850 -hPa surfaces). Outputs are then transformed into water vapor contents above the surface, $850,700,500$, and $300 \mathrm{hPa}$. The surface pressure can take on three different values corresponding to the lower levels of the vertical discretization of the radiative transfer model 4A (1013, 955, and $900 \mathrm{hPa})$. After various tests, we adopted an architecture with one hidden layer (with 15 neurons). No retrieval is attempted in cases where surface pressure is lower than $850 \mathrm{hPa}$. The training of the neural network (Chaboureau et al. 1998a) is performed using the TIGR dataset whose tropical class has been extended to about 900 situations, 
emphasizing more humid atmospheres and a better Gaussian behavior as shown in Fig. 2 (Chevallier et al. 1998). Moreover, to take into account existing discontinuities between the surface skin temperature and the surface air temperature, the skin temperature associated with each extended TIGR (TIGR-3) situation is obtained by adding to the surface air temperature a Gaussian "noise" (random drawing) of standard deviation varying with the situation (airmass type; land/sea flag) from 1.7 to $3 \mathrm{~K}$. Discontinuities are limited to three times the standard deviation.

The entire 3I algorithm is illustrated by a flow diagram in Fig. 1. As seen in this figure, the TIGR dataset plays a key role at many steps of the algorithm. For a weakly nonlinear problem, such as temperature inversion, it is the source of the initial guess solution (through pattern recognition) and of the a priori information (covariances matrices) involved in the Bayesian temperature estimate. For stronger nonlinearities, like water vapor inversion, it is used for training the neural networks from which proceeds the nonlinear water vapor estimate. Transformations from the thermodynamic world (pressure, temperature, water vapor, etc.) to the radiative world may be treated
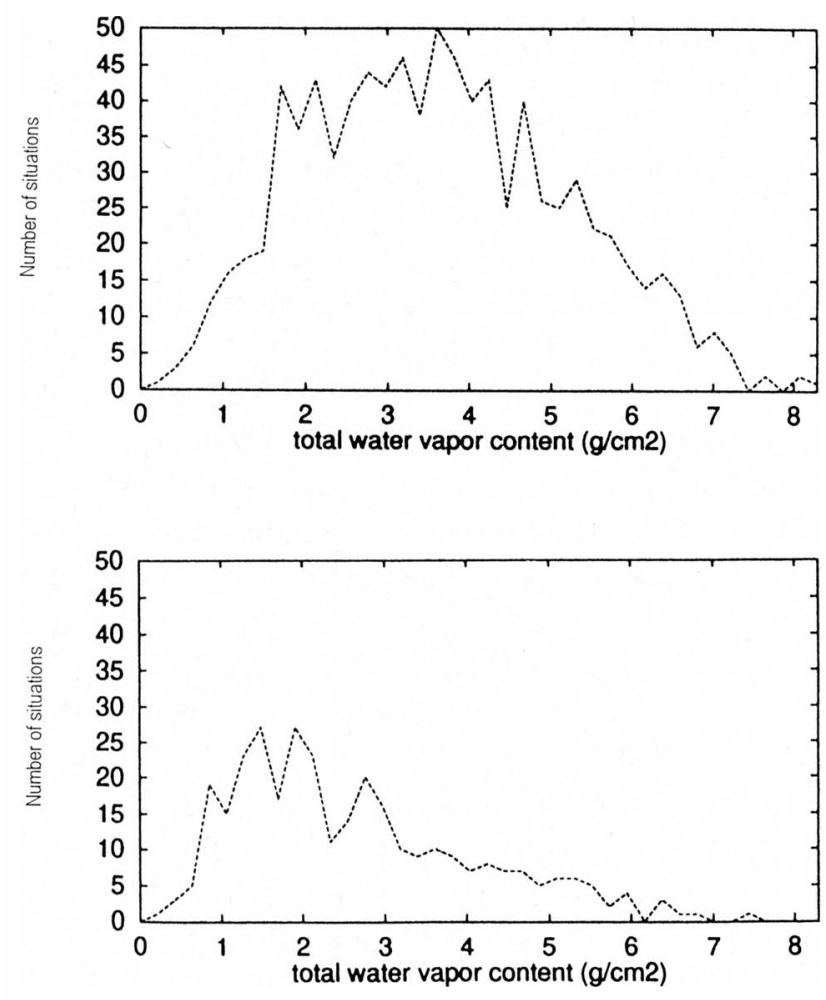

FIG. 2. Histograms (40 classes) of the total water vapor content of the extended tropical class of TIGR (TIGR-3) (top) and in the preceding TIGR-2 tropical class (bottom). the same way. TIGR appears as a sort of "professor" dataset or an atmospheric radiation "interpreter." This is shown in Fig. 3.

\section{l. Vertical atmospheric longwave radiative budget}

The various geophysical variables retrieved from 3I contain most of the information needed to derive the vertical distribution of the atmospheric longwave radiative fluxes. A new generation of radiative transfer models, based on the neural network technique, has been designed with the purpose of computing, as rapidly and accurately as possible, the vertical (upward, downward, net) longwave radiative budget from the top of the atmosphere to the surface, for clear as well as for cloudy situations. Flux profiles may be computed starting either from the thermodynamic description of the situation, or from the observed TOVS radiances. The neural networks are trained using large ensembles of flux profiles computed either with a classic wide band model (Morcrette 1991; Zhong and Haigh 1995), or from a line-by-line model 4A (Scott and Chédin 1981). The dramatic saving of computing time offered by these models (more than 10 times faster than a classic wide band model; $10^{6}$ times faster than a line-by-line model) allows for an improved estimation of the longwave radiative properties of the

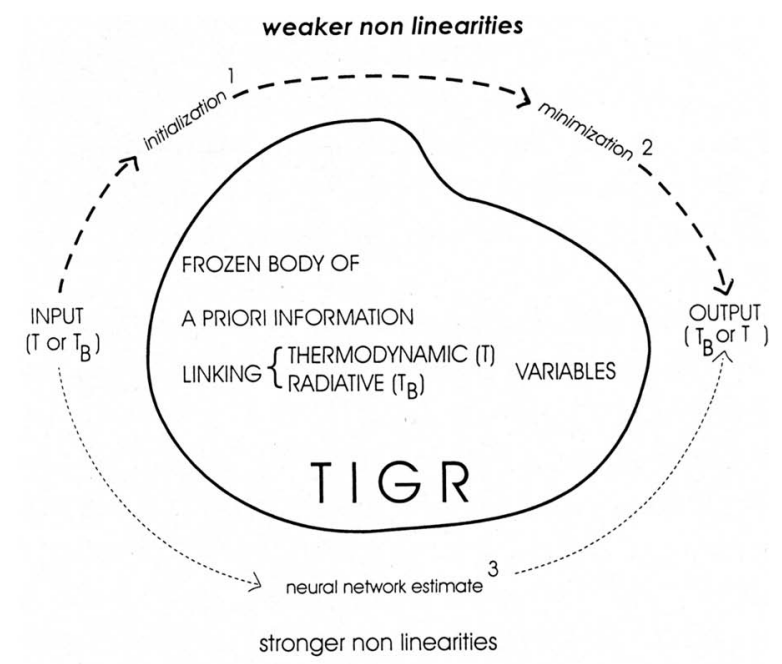

1. pattern recognition (Closest to observation)
2. bayesian estimate (covariance matrices 2. bayesian estimate /coser

FIG. 3. The 3I method of using a priori information from the TIGR dataset. 
atmosphere in general circulation model (GCM) simulations. Details are given in Chevallier et al. (1998), where the validation of these new models is discussed in detail. Flux profiles computed from the TOVS PathB approach are available as "experimental products" upon request from the authors.

\section{The TOVS Pathfinder Path-B Dataset (Level-3 Data)}

The 3I system generates, at global scale, for each $(100 \mathrm{~km} \times 100 \mathrm{~km})$ box, a 297-word output file that includes input data (satellite, ancillary), characteristics of the inversion (multilevel rejection tests), and output products (temperature and moisture profiles, cloud parameters, surface temperature and type, etc.). These level-2 data are archived at LMD. The Pathfinder Path$\mathrm{B}$ (level 3) gridded output file $1^{\circ} \times 1^{\circ}$ follows the conventions and recommendations issued by the TOVS Pathfinder Project.

\section{a. Path- $B$ grid description}

There are 360 cells at the longitude of the first grid cell centered at $179.5^{\circ} \mathrm{W}$ (near the date line), with a grid spacing of $1^{\circ}$. There are 180 cells at the latitude of the first grid cell centered at $89.5^{\circ} \mathrm{S}$ (near the South Pole), with a grid spacing of $1^{\circ}$.

Each level-2 retrieval is assigned to a single grid box. For individual grid boxes with multiple observations, we calculate a simple unweighted average of all values within the box. No interpolation or data filling is done for grid boxes with missing data.

\section{b. Temporal characteristics}

The temporal coverage of this dataset is, at present, from January 1987 to June 1995. Plans for the future include support for the entire TOVS historical record beginning with TIROS- $N$ in November 1978 and continuing to the present. Level-3 gridded data are created at three temporal resolutions: daily, 5-day, and monthly. These products are created separately for the A.M. (descending nodes for morning satellites) and P.M. (ascending nodes for morning satellites) periods for each satellite. Local equator crossing times for even numbered satellites, such as NOAA-10, are nominally 7:30 P.M. for the ascending node and 7:30 A.M. for the descending node. The gridding is based upon the local date and time of the orbits; that is, only those ascending orbits with the same local day and time (which is always 7:30 P.M.) are used in the construc- tion of the P.M. map. A similar procedure is used for the A.M. map.

\section{c. Variable description}

The TOVS Pathfinder Path-B dataset contains 43 retrieved geophysical variables as shown in Table 2 . The TOVS Pathfinder Path-B gridded data are available from the Goddard Space Flight Center (GSFC) Distributed Active Archive Center (DAAC) and from the Centre National de la Recherche Scientifique (CNRS), Laboratoire de Métérologie Dynamique, Ecole Polytechnique, France.

\section{Monitoring of observational and computational biases}

Like most physical retrieval methods, the 3I method estimates geophysical variables by minimizing the differences between a set of observed and computed brightness temperatures. As a consequence, systematic biases between simulated and observed brightness temperatures can be problematic, not only for the retrieval accuracy, but also for further analyses of the climate variability and evolution. As these biases may differ from satellite to satellite, spurious trends may result.

The reanalysis tools (specifically the forward radiative transfer models) not only require exhaustive validation but they also have to be regularly calibrated and adjusted to follow the evolution of the instruments.

Removal of systematic biases, due to either intersatellite changes in the spectral intervals of the channels or to instrumental drifts and individual channel evolution over the lifetime of a given satellite, requires developing an automatic correction scheme to infer and regularly update these adjustments. At LMD, we use collocated satellite-radiosonde datasets from NOAA/NESDIS: the so-called DSD5 files (Uddstrom and McMillin 1993).

From the launch of TIROS-N, NOAA/NESDIS has collected and collocated satellite and radiosonde data. Part of this dataset is illustrated in Table 3. Additional files have been archived by NOAA for NOAA-11 and subsequent satellites starting in mid-July 1992. (E. Brown and C. Paris 1996, personal communication).

Data from various types of scenes may be found in the DSD5 files: cloudy, partly cloudy, and clear; sea and land; day and night.

The nominal DSD5 files contain view-anglecorrected TOVS radiances, together with the indica- 
TABLE 2. TOVS Pathfinder Path-B gridded products.

\begin{tabular}{|c|c|c|c|}
\hline Description & Units & Description & Units \\
\hline Temperature between 1000 and $850 \mathrm{hPa}$ & $\mathrm{K}$ & Precipitable water vapor above surface & $\mathrm{cm}$ \\
\hline Temperature between 850 and $700 \mathrm{hPa}$ & $\mathrm{K}$ & Precipitable water vapor above $850 \mathrm{hPa}$ & $\mathrm{cm}$ \\
\hline Temperature between 700 and $500 \mathrm{hPa}$ & $\mathrm{K}$ & Precipitable water vapor above $700 \mathrm{hPa}$ & $\mathrm{cm}$ \\
\hline Temperature between 500 and $300 \mathrm{hPa}$ & $\mathrm{K}$ & Precipitable water vapor above $500 \mathrm{hPa}$ & $\mathrm{cm}$ \\
\hline Temperature between 300 and $100 \mathrm{hPa}$ & $\mathrm{K}$ & Precipitable water vapor above $300 \mathrm{hPa}$ & $\mathrm{cm}$ \\
\hline Temperature between 100 and $70 \mathrm{hPa}$ & K & Surface skin temperature & K \\
\hline Temperature between 70 and $50 \mathrm{hPa}$ & $\mathrm{K}$ & Total effective cloud amount & $\%$ \\
\hline Temperature between 50 and $30 \mathrm{hPa}$ & $\mathrm{K}$ & Effective cloud amount above $180 \mathrm{hPa}$ & $\%$ \\
\hline Temperature between 30 and $10 \mathrm{hPa}$ & $\mathrm{K}$ & Effective cloud amount between 310 and $180 \mathrm{hPa}$ & $\%$ \\
\hline Virtual temp. between 1000 and $850 \mathrm{hPa}$ & $\mathrm{K}$ & Effective cloud amount between 440 and $310 \mathrm{hPa}$ & $\%$ \\
\hline Virtual temp. between 850 and $700 \mathrm{hPa}$ & $\mathrm{K}$ & Effective cloud amount between 560 and $440 \mathrm{hPa}$ & $\%$ \\
\hline Virtual temp. between 700 and $500 \mathrm{hPa}$ & $\mathrm{K}$ & Effective cloud amount between 680 and $560 \mathrm{hPa}$ & $\%$ \\
\hline Virtual temp. between 500 and $300 \mathrm{hPa}$ & $\mathrm{K}$ & Effective cloud amount between 800 and $680 \mathrm{hPa}$ & $\%$ \\
\hline Virtual temp. between 300 and $100 \mathrm{hPa}$ & $\mathrm{K}$ & Effective cloud amount below $800 \mathrm{hPa}$ & $\%$ \\
\hline Virtual temp. between 100 and $70 \mathrm{hPa}$ & $\mathrm{K}$ & Cloud-top pressure & $\mathrm{hPa}$ \\
\hline Virtual temp. between 70 and $50 \mathrm{hPa}$ & $\mathrm{K}$ & Cloud-top temperature & K \\
\hline Virtual temp. between 50 and $30 \mathrm{hPa}$ & $\mathrm{K}$ & HIRS/2 satellite zenith angle & $\operatorname{deg}$ \\
\hline Virtual temp. between 30 and $10 \mathrm{hPa}$ & $\mathrm{K}$ & Local time of the day & hrs \\
\hline Mean temperature surface to $500 \mathrm{hPa}$ & $\mathrm{K}$ & Quality flag & N/A \\
\hline Mean temperature 500 to $300 \mathrm{hPa}$ & $\mathrm{K}$ & Microwave surface emissivity & $\%$ \\
\hline Mean temperature 300 to $100 \mathrm{hPa}$ & $\mathrm{K}$ & Airmass flag (from 1 to 5 ) & N/A \\
\hline Mean temperature 100 to $30 \mathrm{hPa}$ & $\mathrm{K}$ & & \\
\hline
\end{tabular}

tion of the presence or absence of clouds. Window channels 8,18 , and 19 have also been corrected for water vapor and surface emissivity, which prevents recovery of the original observed radiances. For that reason, a new system of collocation with the radiosondes has been developed (Armante et al. 1998). Latitude, longitude, time, and measurement of the radiosonde are first extracted from the DSD5 archive. Brightness temperature observations are then extracted from the level-1B Pathfinder archive and collocated with the radiosondes (window: $100 \mathrm{~km} \times 3 \mathrm{~h}$ ). Radiosonde reports are screened for quality and the number
TABLe 3. DSD5 Collocation archive at LMD (partial) from Uddstrom and McMillin (1993).

\begin{tabular}{llc}
\hline Satellite & \multicolumn{1}{c}{$\begin{array}{c}\text { Dates of DSD5 } \\
\text { data archive }\end{array}$} & $\begin{array}{c}\text { Number of days } \\
\text { of data }\end{array}$ \\
\hline TIROS-N & $01 / 30 / 1979$ to $03 / 25 / 1980$ & 266 \\
\hline NOAA-6 & $08 / 16 / 1979$ to $08 / 26 / 1986$ & 270 \\
\hline NOAA-7 & $01 / 16 / 1983$ to $02 / 20 / 1984$ & 332 \\
\hline NOAA-9 & $05 / 14 / 1986$ to $04 / 26 / 1988$ & 83 \\
\hline NOAA-10 & $10 / 30 / 1986$ to $09 / 05 / 1991$ & 1290 \\
\hline NOAA-11 & $07 / 19 / 1989$ to $06 / 29 / 1993$ & 604 \\
\hline NOAA-12 & $07 / 17 / 1991$ to $06 / 29 / 1993$ & \\
\hline
\end{tabular}



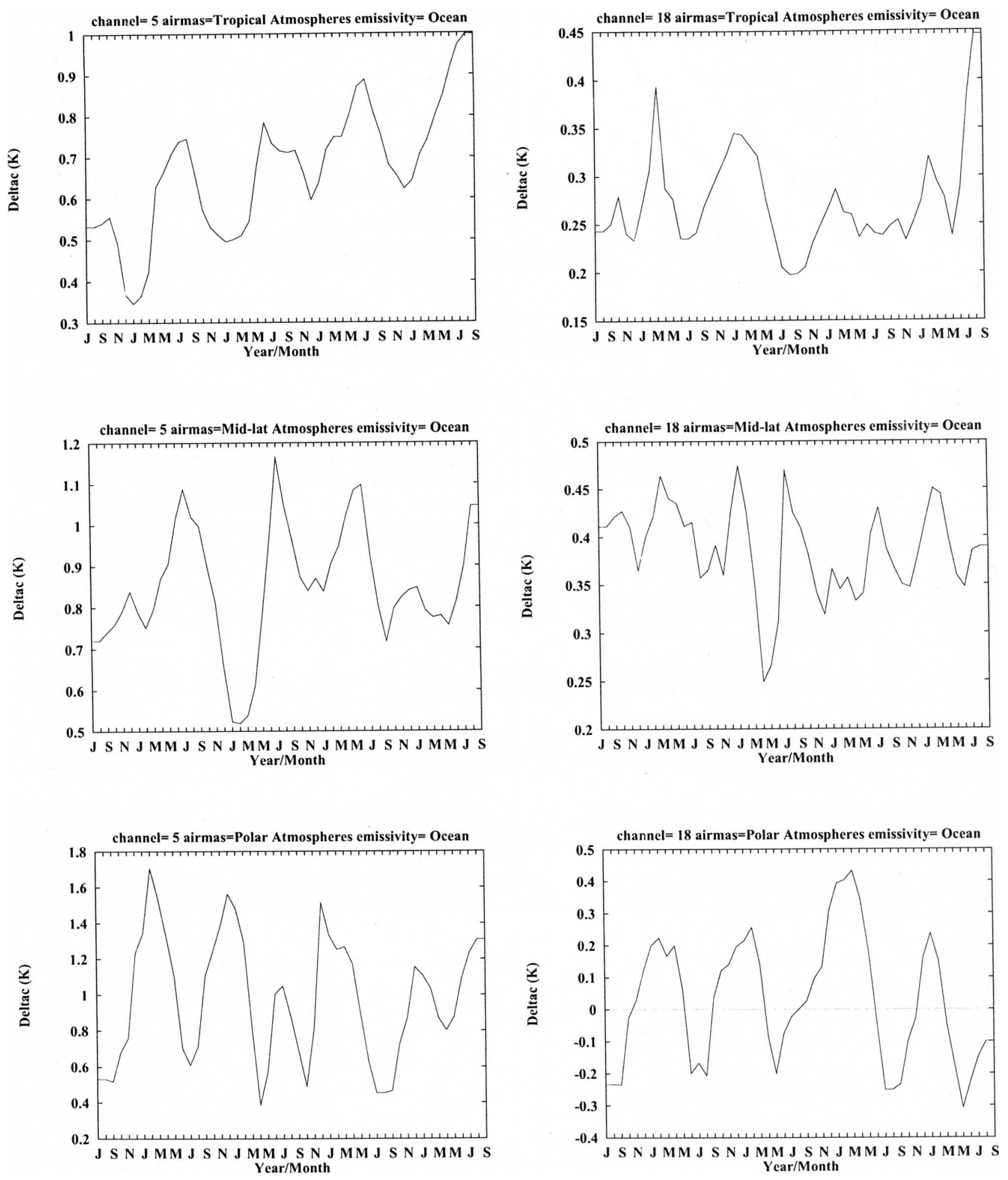

FIG. 4. Empirical adjustment coefficients (the "deltac"s) for two channels of TOVS: channel 5 at $14 \mu \mathrm{m}$ and channel 18 at $4 \mu \mathrm{m}$. The period extends from July 1987 to September 1991.

of reported levels below $30 \mathrm{hPa}$. They are then used as inputs to the forward model, which simulates brightness temperatures for all the infrared and microwave HIRS and MSU channels. Simulated brightness temperatures are compared with observed values. 
Monthly averaged empirical adjustments are computed and stored separately for clear sky, over land, over sea, and for three airmass classes (tropical, midlatitude, polar). Figure 4 shows the results for two channels of HIRS-2, namely, channel 5 (near $14 \mu \mathrm{m}$ ) (Fig. 4, right) and channel 18 (near $4 \mu \mathrm{m}$ ) (Fig. 4, left). The period covered extends from July 1987 to September 1991. These examples are representative of all channels.

This correction procedure allows biases due to the radiative transfer model, to the instrument, or to unexpected events (e.g., the eruption of the Pinatubo volcano) to be taken into account and eliminated quite accurately.

\section{Quality control and validation from the present dataset}

The 3I retrievals are, first, quality controlled using a series of automatic tests:

- check for plausibility (with respect to first guess fields, climatological values, dynamic range simulations from forward modeling);

- check for contradictions (analysis of two or more parameters at the same location: a representative example of such a check - although caricaturalwould be of value of the emissivity, indicating the presence of sea ice while the sea surface temperature is significantly above $273 \mathrm{~K}$ ); and

- check for consistency and spatial continuity (values of some variables at adjacent points usually are only slightly different from each other).

Retrieved variables are validated against independently measured (in situ or satellite retrieved) or analyzed data:

- raobs and conventional analyses for temperature profiles;

- raobs, analyses, and SSM/I data for moisture profiles;

- in situ data, observations from the Advanced Very High Resolution Radiometer (AVHRR), and climatological analyses for sea surface temperatures (SST);

- ISCCP data for cloud characteristics; and

- ERBE data for longwave radiative fluxes (derived from the retrieved thermodynamic variables).
Examples of product outputs and illustrations of these comparisons are shown in this section and more details are given in quoted references.

\section{a. Atmospheric layer average temperatures}

The 3I retrieved temperatures have been compared to collocated radiosonde data. Because the same archive is used to determine the empirical adjustments applied to the computed brightness temperatures, statistics resulting from such comparisons allow the bias and the noise (standard deviation) introduced by the inversion scheme to be quantified. The period of comparison extends over 51 months from July 1987 to September 1991 and the retrievals are from NOAA-10. The collocation window is $100 \mathrm{~km} \times 3 \mathrm{~h}$. Results are given in Table 4 for eight layers from the surface to $10 \mathrm{hPa}$, first globally and then for each airmass type: tropical, midlatitude, and polar. The results yield the following conclusions.

- The biases are relatively small except for the highest layer (30-10 hPa), which is at the limit of the HIRS-2 capabilities, for the midlatitudes. The two lowest layers (1000-850 hPa and $850-700 \mathrm{hPa}$ ) in polar latitudes also exhibit larger biases owing to the presence of strong temperature inversions, whose vertical extent is often below the vertical resolution of the instrument. A significant bias $(0.92 \mathrm{~K})$ is also observed for the sharper tropical tropopause around $100 \mathrm{hPa}$ for the same reason.

- As expected (vertical resolution inherently too low), the largest standard deviations are found for the lowest layer (1000-850 hPa) and for the highest layer (30-10 hPa). Otherwise, the mean standard deviation is $1.45 \mathrm{~K}$ for the tropical situations, $1.62 \mathrm{~K}$ for the midlatitudes, and $1.72 \mathrm{~K}$ for the polar cases. On the whole, these results may be considered satisfactory. Relatively good results have also been obtained over Antarctic conditions (Heinemann et al. 1994; Kopken et al. 1995).

\section{b. Stratospheric temperatures}

The importance of the stratosphere in the study of climate variability and trends has led us to pay particular attention to assessing the quality of stratospheric temperatures. For that purpose we compared monthly mean temperatures retrieved by 3I with those obtained at Free University (FU) Berlin for the Northern Hemisphere (Fig. 5). The FU Berlin monthly mean temperatures are deduced from daily analyzed temperatures for 0000 UTC, which result from a subjec- 
TABLE 4. Comparison between layer-mean temperatures retrieved from 3I/NOAA-10 and observed by radiosondes. Biases (3I minus radiosondes) and standard deviations (std dev) are in $\mathrm{K}$. The collocation window is $100 \mathrm{~km} \times 3 \mathrm{~h}$. Statistics are computed after a $2 \sigma$ elimination of the poorest collocations.

\begin{tabular}{|c|c|c|c|c|c|c|c|c|c|c|c|c|}
\hline \multirow[b]{2}{*}{$\begin{array}{l}\text { Layer } \\
(\mathrm{hPa})\end{array}$} & \multicolumn{3}{|c|}{ Global } & \multicolumn{3}{|c|}{ Tropical } & \multicolumn{3}{|c|}{ Mid-latitude } & \multicolumn{3}{|c|}{ Polar } \\
\hline & $\begin{array}{c}\text { Bias } \\
(\mathbf{k})\end{array}$ & Std dev & Sample & $\begin{array}{c}\text { Bias } \\
\text { (k) }\end{array}$ & Std dev & Sample & $\begin{array}{c}\text { Bias } \\
\text { (k) }\end{array}$ & Std dev & Sample & $\begin{array}{c}\text { Bias } \\
\text { (k) }\end{array}$ & Std dev & Sample \\
\hline $30-10$ & 1.09 & 2.27 & 8888 & 0.22 & 1.93 & 3279 & 1.76 & 2.24 & 4635 & 0.82 & 2.87 & 960 \\
\hline $50-30$ & 0.36 & 1.95 & 34315 & 0.02 & 1.91 & 18708 & 0.82 & 1.92 & 12897 & 0.69 & 2.09 & 2672 \\
\hline $100-50$ & 0.61 & 1.39 & 39079 & 0.92 & 1.45 & 21166 & 0.30 & 1.25 & 14735 & 0.13 & 1.44 & 3205 \\
\hline $300-100$ & 0.31 & 1.21 & 48652 & 0.51 & 1.10 & 25584 & 0.18 & 1.31 & 18738 & -0.35 & 1.23 & 4301 \\
\hline $500-300$ & -0.07 & 1.64 & 49252 & -0.38 & 1.39 & 25964 & 0.27 & 1.88 & 18950 & 0.56 & 1.82 & 4413 \\
\hline $700-500$ & -0.61 & 1.40 & 49286 & -0.58 & 1.26 & 25931 & -0.61 & 1.50 & 18902 & -0.81 & 1.78 & 4422 \\
\hline $850-700$ & -0.17 & 1.79 & 48698 & 0.05 & 1.62 & 25609 & -0.20 & 1.88 & 18698 & -1.45 & 1.98 & 4391 \\
\hline $1000-850$ & -0.08 & 2.46 & 39963 & 0.21 & 2.16 & 21581 & -0.34 & 2.75 & 14993 & -1.16 & 2.95 & 3431 \\
\hline
\end{tabular}

tive analysis, using the radiosonde observations over land and the routinely transmitted SATEMs (i.e., thicknesses derived from SSU) over sea, assuring a backward time consistency (Pawson and Naujokat 1997). Since Berlin data are for levels and not layers, mean temperatures have been deduced, assuming that the temperature within a layer varies linearly with altitude between two given levels. In addition, because
10-hPa temperatures from FU Berlin are only between September and March, comparisons for the layer $30-10 \mathrm{hPa}$ are restricted to these winter months. Finally, comparisons have been performed on a grid of $5^{\circ}$ latitude by $5^{\circ}$ longitude, which corresponds to the spatial resolution of Berlin data; consequently, the TOVS/3I temperatures have been interpolated to this grid. Whereas comparisons were made for the whole
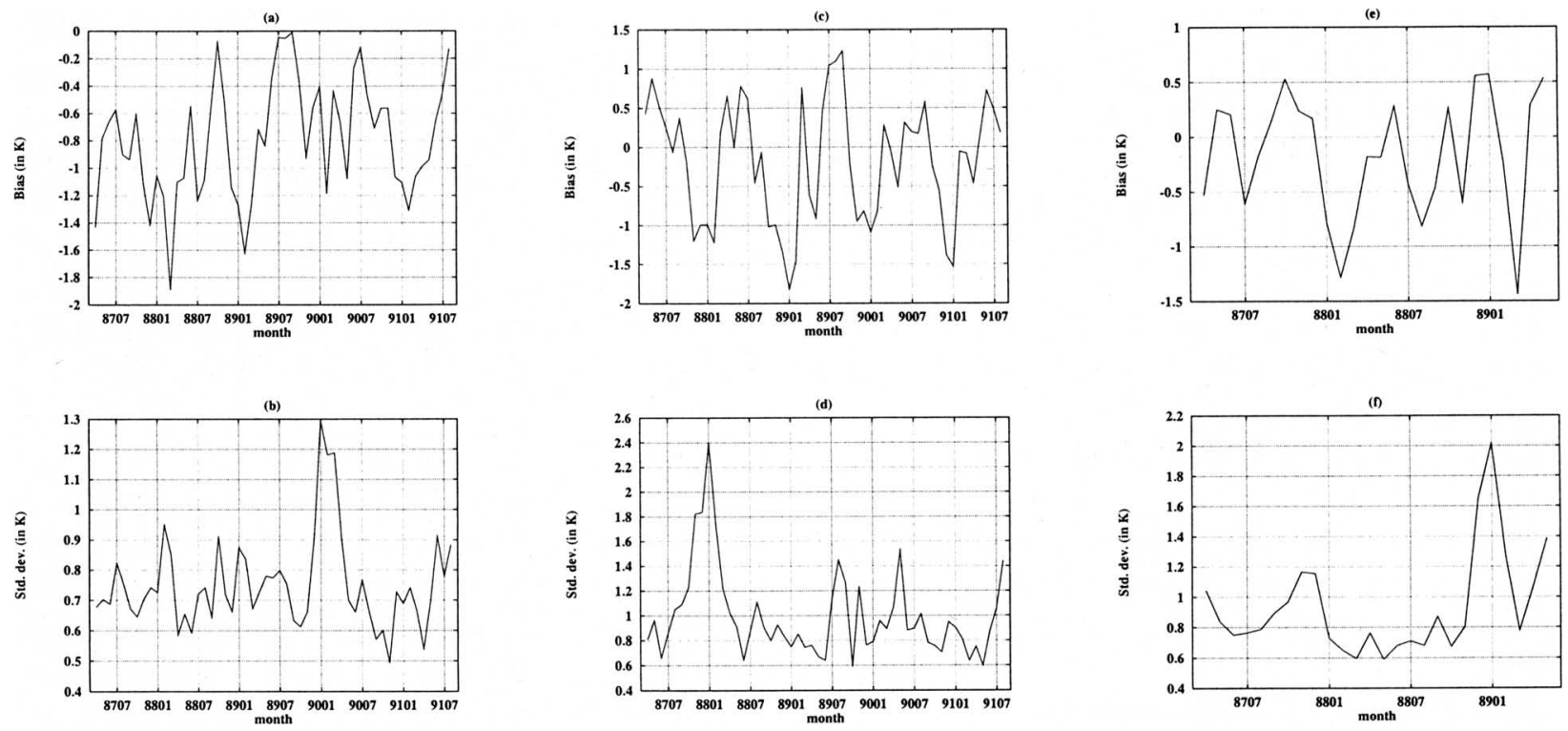

FIG. 5. Statistics (in K) for the Northern Hemisphere $\left(0^{\circ}-30^{\circ} \mathrm{N}\right)$ of the difference (3I minus Berlin analysis) in monthly temperatures for the layers (a)-(b) 100-50, (c)-(d) 50-30, and (e)-(f) 30-10 hPa. Reported are the biases and the standard deviations (std dev). The number of items entering the statistics is 1296. The period covered ranges from April 1987 to August 1991. 
Northern Hemisphere (all latitudes), we present and discuss here only the results obtained over the latitude band spreading from the equator to $30^{\circ} \mathrm{N}$. Statistics (bias and standard deviation) for the layers 100-50, $50-30$, and $30-10 \mathrm{hPa}$ are shown in Fig. 5. The 100$50 \mathrm{hPa}$ layer is characterized by a systematic negative bias (TOVS/3I less than Berlin) of about $-0.8 \mathrm{~K}$, while the standard deviation is $0.7 \mathrm{~K}$ (Figs. 5a,b). The negative bias is probably due to a mislocation of the tropical tropopause, as it is not present for extratropical regions (statistics not shown).

In the layer 50-30 hPa (Figs. 5c,d), the bias between the two products exhibits a kind of seasonal cycle with TOVS/3I temperatures generally more extreme than Berlin ones (colder during winter, warmer during summer); however, both the bias and the standard deviation remain low, with the exception of 1987/88 winter months, where the latter increases to values larger than $1.7 \mathrm{~K}$.

Finally, comparisons for the layer $30-10 \mathrm{hPa}$ (Figs. 5d,e) also exhibit a mean bias less than or of the order of $1 \mathrm{~K}$, while the standard deviation, which is on average $0.8 \mathrm{~K}$, becomes larger in October and November 1990 (1.7 and $2 \mathrm{~K}$ ).

Accounting for time differences, different spatial resolutions, and assumptions made concerning the vertical variation of the temperature between two levels, the agreement between the two records is satisfactory.

A good illustration of the variability of the low stratosphere in the tropical belt $\left(30^{\circ} \mathrm{S}-30^{\circ} \mathrm{N}\right)$ is provided by the Hovmoller diagram for the layer $70-50 \mathrm{hPa}$ using meridian mean values for the period April 1987-August 1991, displayed in Fig. 6. The seasonal cycle appears clearly with minimum temperatures corresponding to northern winter months. In addition to the interannual variations, zonal variations can be seen. The area between about $120^{\circ} \mathrm{E}$ and $180^{\circ}$, for example, is colder during northern winter months than the remaining tropical belt. These features are discussed in more detail in Claud et al. (1999).

\section{c. Sea surface temperature}

Comparisons have been made between Path-B retrieved SSTs and values produced by the PathfinderAVHRR project (Vasquez et al. 1998). Figure 7 presents statistics of the differences between Path-B and AVHRR-retrieved SST (monthly means) for the period July 1987-June 1991 as a function of the sea surface temperature. The observations processed by Path-B are from NOAA-10 while AVHRR data are from $N O A A-9$. The mean bias is close to $-0.3 \mathrm{~K}$ or less for SSTs between 277 and $297 \mathrm{~K}$. Positive biases are observed for SSTs close to $275 \mathrm{~K}$ and larger negative biases (up to $-0.5 \mathrm{~K}$ ) are observed for SSTs over $302 \mathrm{~K}$. The standard deviation peaks at $1.1 \mathrm{~K}$ at $280 \mathrm{~K}$ and has a minimum value of about $0.5 \mathrm{~K}$ at $298 \mathrm{~K}$. Similar results were obtained for NOAA-12 and for the period extending from July 1991 to August 1993.

El Niño is one of the most important known multiyear climate phenomena. The whole planet can be affected by serious meteorological consequences as seen recently with the last event (1997/98). More than $10 \mathrm{El}$ Niños have been recorded in the past 40 years. Strongest recent occurrences were this year and in $1982 / 83$. The $1986 / 87$ event, although weaker, was



FIG. 6. Hovmoller diagram (time vs longitude) of the 70-50-hPa layer temperature for the period April 1987-August 1991. 
(a)

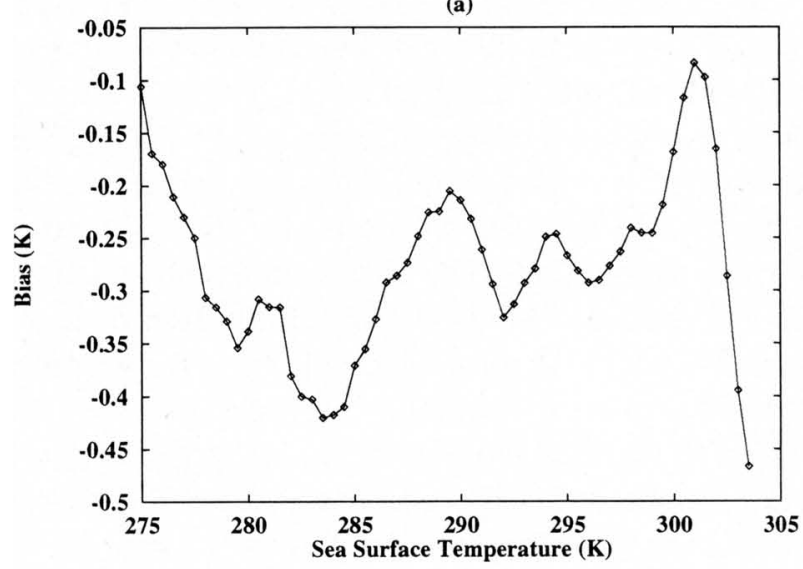

(b)

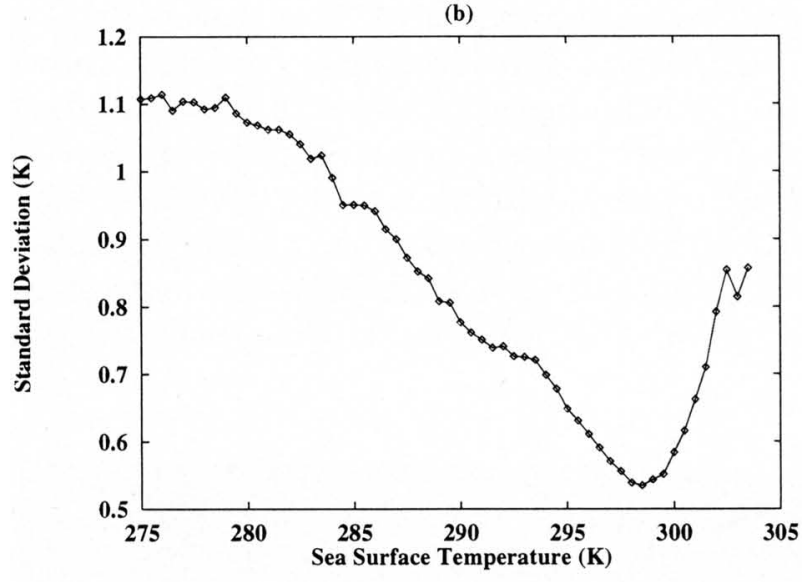

(c)

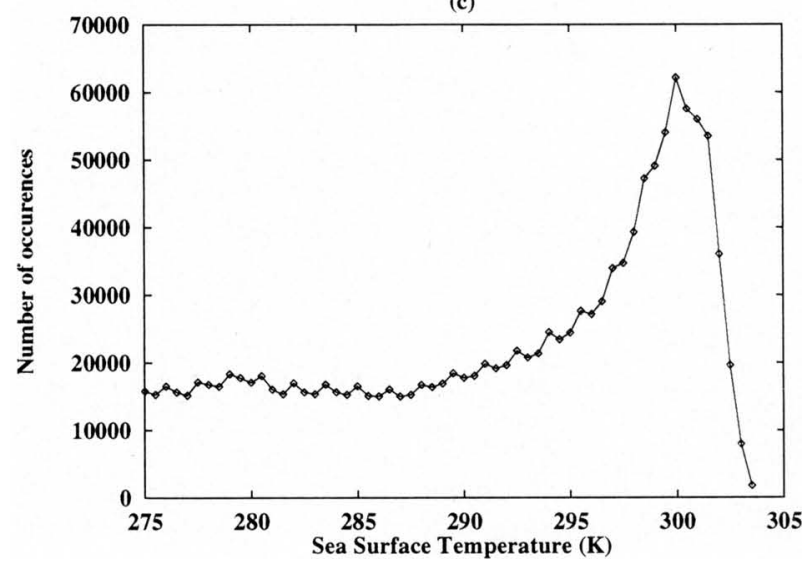

FIG. 7. Statistics for the difference between Path-B and Pathfinder-AVHRR retrieved SSTs for the period July 1987-June 1991 as a function of the SST. Path-B observations are from NOAA-10; Pathfinder-AVHRR observations are from NOAA-9. (a) Bias, (b) standard deviation, and (c) number of samples. very significant and occurred within the presently reprocessed Path-B period. We compared its signature on SST maps from the TOVS Path-B results and from Pathfinder-AVHRR. Figure 8 presents the difference between the monthly mean sea surface temperature from Path-B for April 1987 and April 1989, a non-El Niño year. In Figure 9, the same results are presented for Pathfinder-AVHRR. The main features of both datasets agree well. Differences lie in the availability of data points for cloudy situations (after cloud clearing) and over land from Path-B (although less reliable), leading to more samples in the statistics, but to higher noise than from AVHRR.

\section{d. $3 D$ water vapor distribution}

To assess the quality of 3I water vapor retrievals, we performed local and global comparisons with various independent sources of information.

Figure 10 shows the total precipitable water vapor contents from radiosondes for the period between July 1987 and December 1988 compared with retrievals from SSM/I (Bauer and Schluessel 1993) and TOVS (3I, NOAA-10). The space-time collocation window is $50 \mathrm{~km}$ by $1 \mathrm{~h}$, and the number of collocations is 1476. The mean and standard deviation of the differences are -0.01 and $0.47 \mathrm{~cm}$ from SSM/I retrievals versus radiosonde data, and -0.06 and $0.55 \mathrm{~cm}$ for TOVS retrievals versus radiosonde data. The biases are small in both comparisons, and the standard deviation is about $20 \%$ of the mean value of the precipitable water observed from sondes.

Table 5 presents comparisons between total and layer average contents from TOVS and from radiosondes. The number of samples is larger than for the previous comparison because it is easier to collocate observations from only two systems, and also because the temporal period, not limited by the SSM/I data availability, has been extended from April 1987 to October 1989. Owing to the rapid decrease of water vapor with altitude, results are given in relative value (percent of the mean layer content from radiosondes). Statistics are given after a 2-sigma elimination, removing the collocations (about 5\%) for which the water vapor difference is more than two times the standard deviation (sigma) away from the average difference. While most biases remain small standard deviations increase, as expected, from the surface to the highest layer (500-300 hPa) and from tropical to polar situations. The well recognized low reliability of radiosonde measurements in cold, dry conditions largely explains this tendency (Elliott and Gaffen 1991). 
Consequently, poorest results are obtained for the layer 500-300 hPa.

For a more comprehensive validation of TOVS-3I, we have compared the monthly average total water vapor content from TOVS-3I and from SSM/I, according to the value of the sea surface temperature (SST) (Fig. 11). The temporal period is from July 1987 to December 1988. Over this period, the bias oscillates around zero (from about -0.2 to $+0.2 \mathrm{~cm})$. The standard deviation reaches its peak value of about $20 \%$ around $20^{\circ} \mathrm{C}$. For SSTs greater than $25^{\circ} \mathrm{C}, \mathrm{SSM} / \mathrm{I}$ estimation of the total precipitable water is larger than the 3 I value by a few millimeters; the standard deviation is close to $10 \%$. The overestimation of TOVS/3I versus $\mathrm{SSM} / \mathrm{I}$ in the $15^{\circ}-25^{\circ} \mathrm{C}$ range is mostly due to maritime stratocumulus clouds $(\mathrm{mSc})$ located primarily off the coasts of California, Chile, Mauritania, and Angola. More details are given in Chaboureau et al. (1998a; see also Chaboureau et al. 1998b).

We have also examined the time evolution of the global retrieval total water vapor content for springsummer 1987 and 1988, where 1987 shows significant perturbations related to the El Niño warm event (Krishnamurti et al. 1989). We have focused our attention on the Indian monsoon. The yearly phenomenon of the monsoon occurs as a spectacular change in convective activity, especially between India and Australia. In February and March the intense convection is located roughly at a latitude ranging between $5^{\circ} \mathrm{N}$ and $20^{\circ} \mathrm{S}$ in the central and eastern Indian Ocean and Indonesia. During the following months, the extension and intensity of the convection increase as it migrates northward, reaching its culmination in July-August. The average rate of monthly precipitation can reach $25 \mathrm{~mm}$ per day in certain zones. The convection gradually decreases and returns toward the Southern Hemisphere. The 1987 El Niño event caused a year full of perturbations with, in particular, significant deficits in precipitation over south, eastern, and southeast Asia (Krishnamurti et al. 1989). Figures $12 \mathrm{a}-\mathrm{d}$ shows maps of the total water vapor content for April 1987, April 1988, August 1987, and August 1988, respectively. In April 1987, contrary to April 1988, the northward migration has not started, and the atmosphere above India and southeast Asia, in particular, appears very much drier. In August, more normal developments are observed, although the area covered by large amounts of water vapor (above $5.5 \mathrm{~cm}$ ) is still significantly smaller in 1987 than in 1988.

\section{e. Cloud characteristics}

The relatively good spectral resolution and many

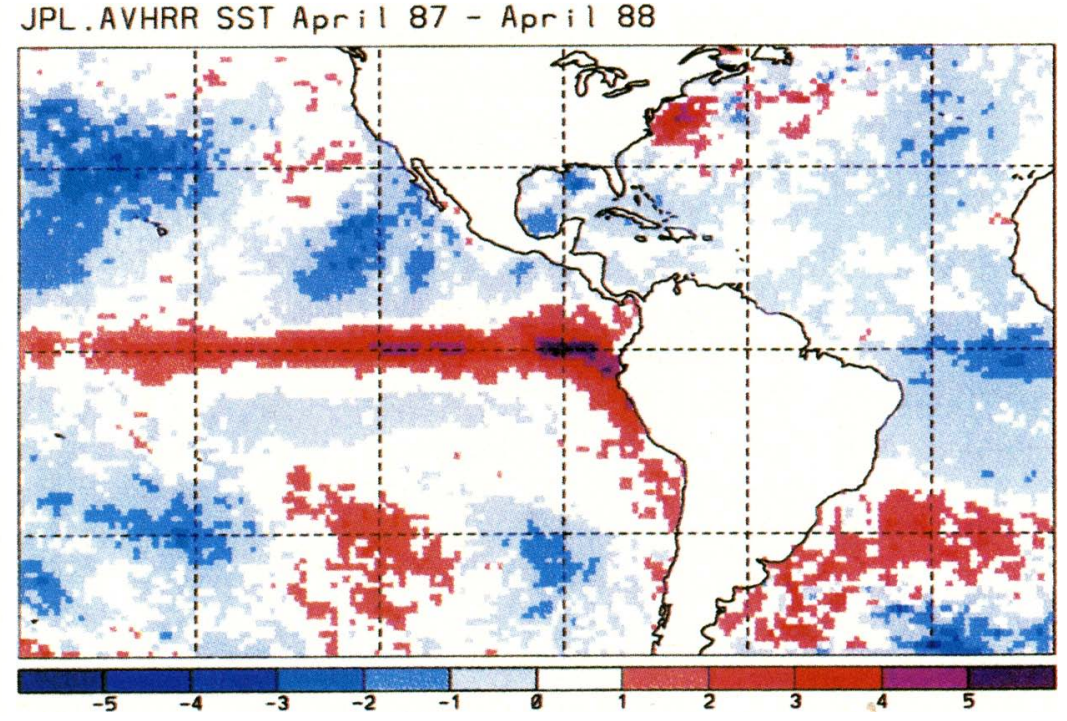

FIg. 9. Same as Fig. 8 for Pathfinder-AVHRR. 
(a)

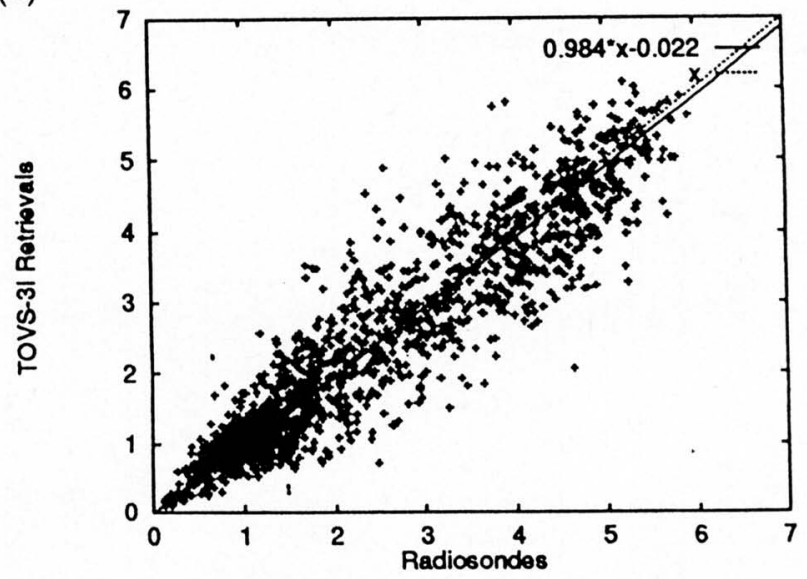

(b)

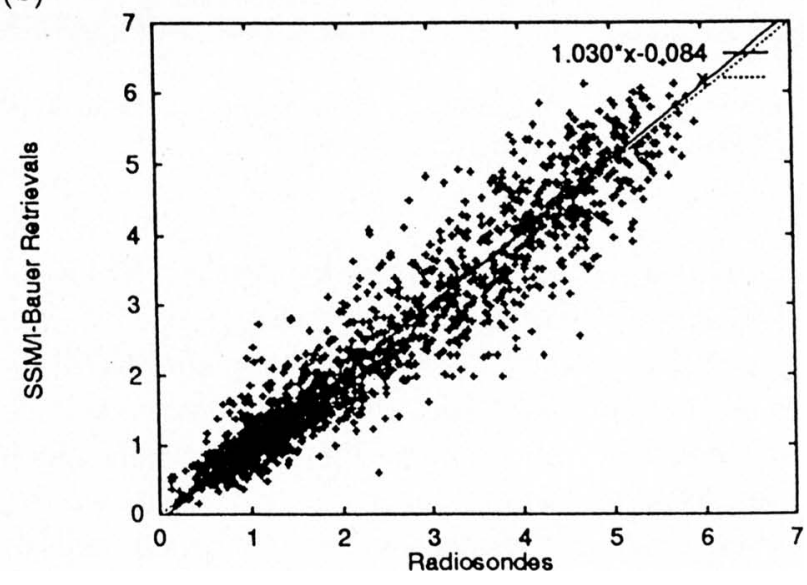

Fig. 10. Scatterplot of precipitable water $(\mathrm{cm})$ from radiosondes versus (a) TOVS-3I and (b) SSM/I-Bauer. The line of perfect fit $(\times)$ and a least squares regression line are also plotted.

channels in infrared (IR) sounders make them a very useful tool for the determination of cloud properties both day and night.

Figure 13 shows geographical maps of monthly most frequent cloud types over the globe in July 1987 and in January 1988 at 7:30 A.M. local time, obtained from the 3I cloud scheme (Figs. 13b,d) and from ISCCP (Figs. 13a, c). For clarity, we consider only six different cloud types distinguished by cloud-top pressure (midlevel clouds have tops between 680 and $440 \mathrm{hPa}$ ) and two effective cloud amount intervals (divided at 0.9 for high clouds and at 0.5 for midlevel and low clouds). Note that at 7:30 A.M. local time there is daylight only in the summer hemisphere. The ISCCP analysis determines optical thickness for each cloudy pixel (day only) and can be used to estimate cloud cover from the number of cloudy pixels within the $1^{\circ}$ $\times 1^{\circ}$ grid. If the average optical thickness $\tau$ is less than
9.4, or the cloud cover is less than 0.5 (for midlevel or low clouds), then the ISCCP clouds are classified in the lower opacity category. To approximate the 3I cloud types with the ISCCP results, the cloud-top pressure category is determined by the most frequent value of cloud-top pressure within the $1^{\circ}$ grid.

The ISCCP cirrus identification (in daytimesummer hemisphere) in general agrees well with the 3I cirrus identification. At night (winter hemisphere), however, 3I cirrus information significantly widens the ISCCP results. In July there are mostly cirrus over the Northern Hemisphere land, whereas in winter these regions are more frequently covered by midlevel and low clouds. In general, the 3I cirrus zone around the Intertropical Convergence Zone (ITCZ) is broader in meridional extent than the ISCCP cirrus zone. An interesting feature is the appearance of cirrus clouds off the eastern North American coast in July, which is confirmed by the HIRS analysis of Wylie and Menzel (1999), but not as well identified by ISCCP in the morning hours. A possible reason for this difference could be that low-level clouds lie underneath these cirrus, so that ISCCP would have difficulties in identifying cirrus correctly (Jin and Rossow 1997).

With 3I, one can recognize the Southern Hemisphere storm track zone and the Northern Atlantic storm track in winter. During summer, these zones are covered mostly by midlevel and low-level clouds. The earth's deserts are cloudier in July than in January according to 3I, in agreement with climatological surface observations (Warren et al. 1986). When there are clouds, they are mostly cirrus in summer, and a mixture of low clouds and cirrus in winter. ISCCP finds a predominance of low clouds in summer, but clear sky and cirrus in winter. The more prevalent cumulus clouds in summer in the ISCCP results may arise from its detection of dust storms. Stratus clouds in the marine stratocumulus regions off the western coasts of California, South America, Namibia, and Australia appear well in the ISCCP dataset and in the 3I dataset. All the other oceanic regions are covered mostly by low-opacity, low-level clouds (i.e., cumulus).

Another way to use combined information about cloud height and opacity is to compare distributions of cloud-top pressure weighted by effective cloud amounts. These are shown in Figs. 14a-d, as obtained by ISCCP and 3I, for four different geographical regions. The 3I distributions show a bimodal structure with peaks around high- and low-level clouds, in agreement with observations by Susskind et al. (1997). The heights of these peaks depend on the geographi- 
TABLE 5. Comparison of total and layer average water vapor contents from TOVS-3I and from radiosondes, according to air masses, covering the 3I months from April 1987 to October 1989. The bias and standard deviations are expressed in percent of the mean layer water vapor content from radiosondes (after a $2 \sigma$ elimination of the poorest collocations).

\begin{tabular}{|c|c|c|c|c|c|c|c|c|c|c|c|c|}
\hline \multirow[b]{2}{*}{ Layer } & \multicolumn{3}{|c|}{ All situations } & \multicolumn{3}{|c|}{ Tropical situations } & \multicolumn{3}{|c|}{ Midlatitude situations } & \multicolumn{3}{|c|}{ Polar situations } \\
\hline & Sample & Bias & Std dev & Sample & Bias & Std dev & Sample & Bias & Std dev & Sample & Bias & Std dev \\
\hline $1000-300$ & 8547 & -1.9 & 20.2 & 3960 & 0.4 & 17.5 & 3189 & -5.4 & 24.6 & 1479 & -15.1 & 26.9 \\
\hline $1000-850$ & 8511 & -7.1 & 22.3 & 3966 & -7.1 & 20.0 & 3195 & -8.0 & 23.9 & 1477 & -20.4 & 33.5 \\
\hline $850-700$ & 8527 & -1.8 & 28.1 & 3964 & 2.4 & 25.0 & 3175 & -8.2 & 31.9 & 1467 & -17.5 & 31.7 \\
\hline $700-500$ & 8513 & 6.4 & 39.1 & 3980 & 15.1 & 36.2 & 3198 & -2.8 & 34.8 & 1467 & -9.0 & 30.0 \\
\hline $500-300$ & 8512 & 3.8 & 39.3 & 3945 & -0.9 & 34.8 & 3209 & 14.6 & 45.8 & 1481 & 12.4 & 51.6 \\
\hline
\end{tabular}

cal region. ISCCP produces distributions with one broad maximum. Before coming to conclusions, one has to be careful about systematic differences in atmospheric temperature profiles used to create each dataset. The
ISCCP method incorporates NOAA-produced operational TOVS profiles to transform the measured ISCCP cloud-top temperature into cloud-top pressure. In contrast, the 3I method converts cloud-top pressure
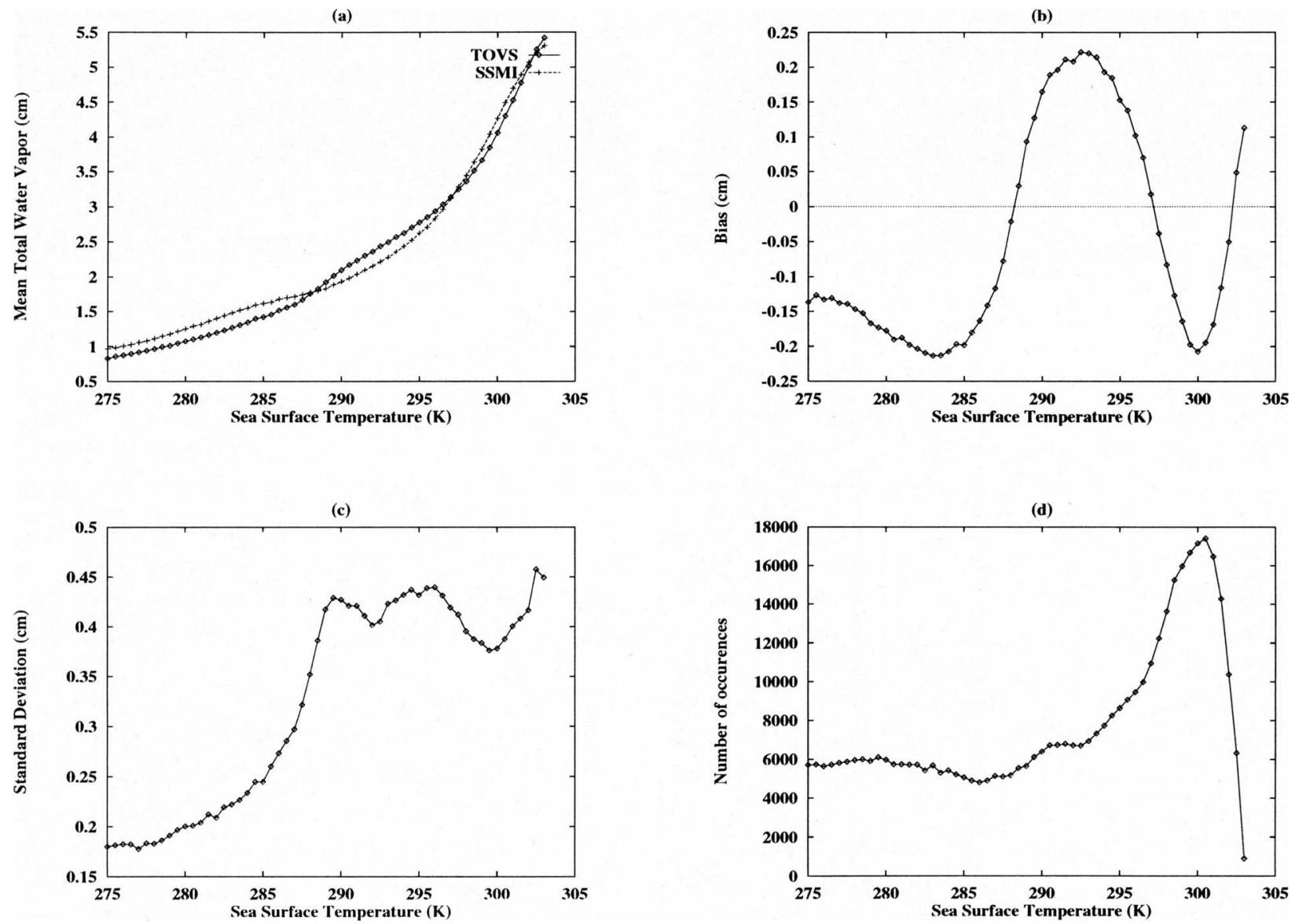

FIG. 11. The 17-month (July 1987 to December 1988, except December 1987) average total precipitable water from TOVS-3I and from SSM/I-Bauer according to (a) sea surface temperature, (b) bias (TOVS minus SSM/I), (c) standard deviation, and (d) number of grid points. 

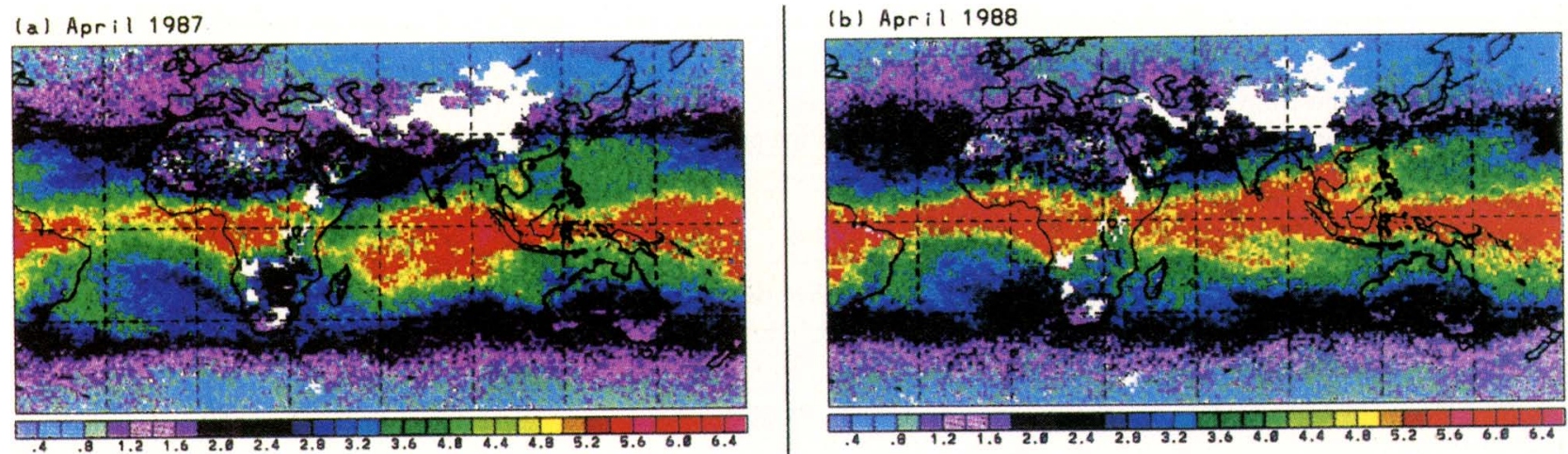

(c) August 1987
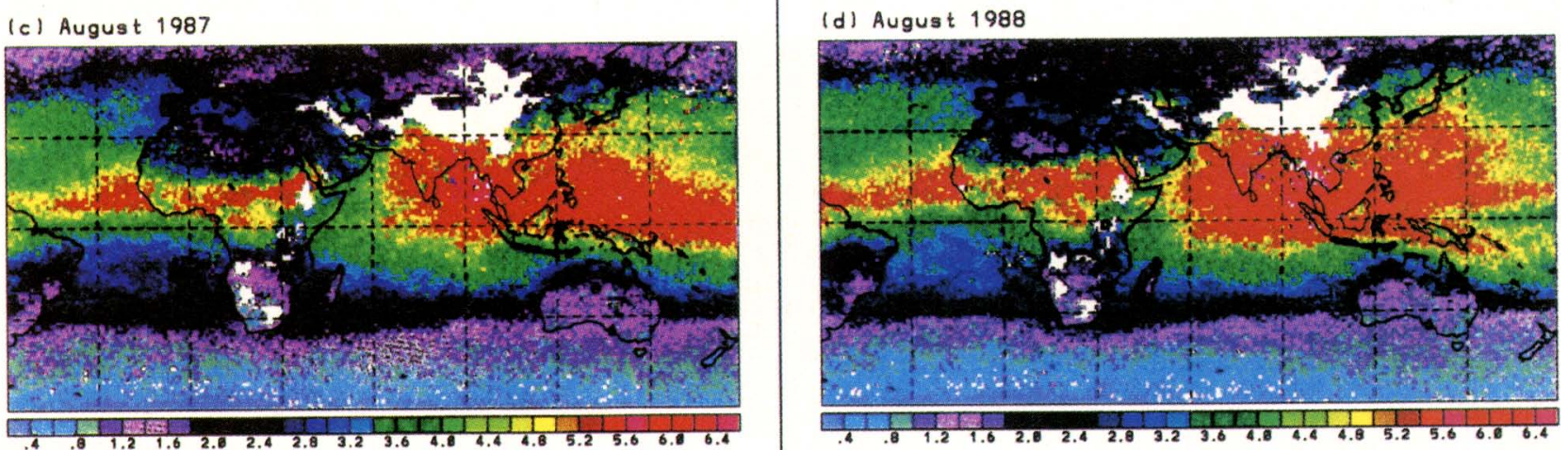

FIG. 12. Maps of the Path-B retrieved total water vapor content for (a) April 1987, (b) April 1988, (c) August 1987, and (d) August 1988.

into cloud-top temperature using 3I-derived temperature profiles. Indeed, the effective-cloud-amount-weighted cloud-top temperature distributions determined by $3 \mathrm{I}$ and ISCCP in Figs. 15a-d agree better than the pressure distributions. Remaining differences in the midlatitudes can be accounted for by lower effective cloud amounts from 3I at lower temperatures due to heterogeneous cloud scenes, and in the tropical "warm pool" where one expects to encounter low-level clouds underneath cirrus clouds about $30 \%$ of the time (Jin and Rossow 1997). ISCCP misidentifies these regions as partly cloudy low-level clouds.

More details are given in Stubenrauch et al. (1999ac). An interesting outcome of these studies is that small-scale heterogeneities, both horizontal and vertical, play an important role in determining the relationship between cloudy information obtained from infrared sounders (3I) and imagers also using visible radiance measurements (ISCCP). When cirrus overlie low-level clouds, the infrared sounder-derived cloud properties are dominated by the properties of the uppermost cloud layer, whereas the visible radiance measurements used by ISCCP include, and may be dominated by, the properties of the lowermost cloud layer, producing a larger effective cloud amount for ISCCP.

\section{f. Outgoing longwave radiative fluxes}

Compared with the observations, the fluxes computed from the 3I products enable an indirect validation of the 3I method. An example is given here of the Outgoing Longwave Radiance (OLR). Indeed, the ERBE instruments, flown on $N O A A-9$ and $N O A A-10$, together with the TOVS, allow comparisons between the instantaneous estimation of the OLR from 3I and from ERBE (ERBE S8 product).

Table 6 illustrates the comparison between the two 
quantities in clear skies, for four months worth of data collected from NOAA-10: July 1987, October 1987, January 1988, and April 1988. Distinctions are made between the land and sea geotypes, and between the morning and evening orbits. The collocation algorithm is described in Stubenrauch (1993). On average, the mean absolute bias is about $2 \mathrm{~W} \mathrm{~m}^{-2}$, varying between about +5 to $-4 \mathrm{~W} \mathrm{~m}^{-2}$. The mean standard deviation is on the order of $6 \mathrm{~W} \mathrm{~m}^{-2}$. Computed results explain more than $97 \%$ of the ERBE variance on average.

These differences have four primary causes:

- errors in retrievals by $3 \mathrm{I}$;

- errors in the interface between 3I, which retrieves water vapor contents in four coarse layers, and the flux model in which discretization is much thinner (assumptions have to be made on the shape of the profile);

- errors due to the model itself (less than $2 \mathrm{~W} \mathrm{~m}^{-2}$ at the top of the atmosphere); and

- errors linked to the ERBE processing. Wieklicki et al. (1995) report calibration errors of the order of $2.4 \mathrm{~W} \mathrm{~m}^{-2}$ and angular model errors of the order

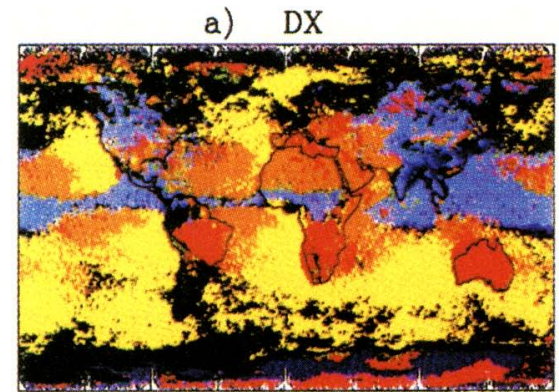

b) $3 \mathrm{I}$

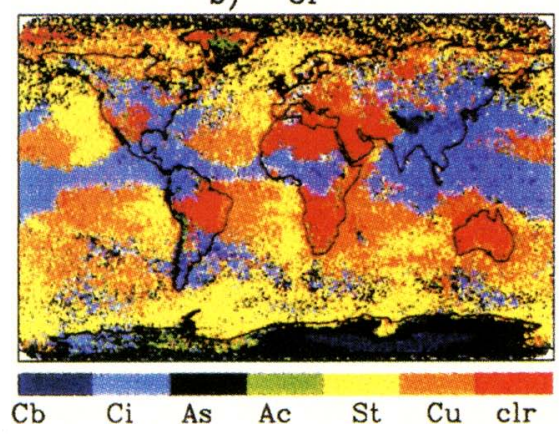

FIG. 13. Geographical maps of the most frequent cloud type at 7:30 A.M. local time in July 1987 (daylight on Northern Hemisphere) (a), (b); and in (c), (d) January 1988 (daylight on Southern Hemisphere) with cloud types identified by (b), (d) 3I, and (a), (c) ISCCP. Six cloud types are considered: high opaque (Cb), cirrus (Ci), altostratus (As), altocumulus (Ac), stratus ( $\mathrm{St})$, and cumulus $(\mathrm{Cu})$

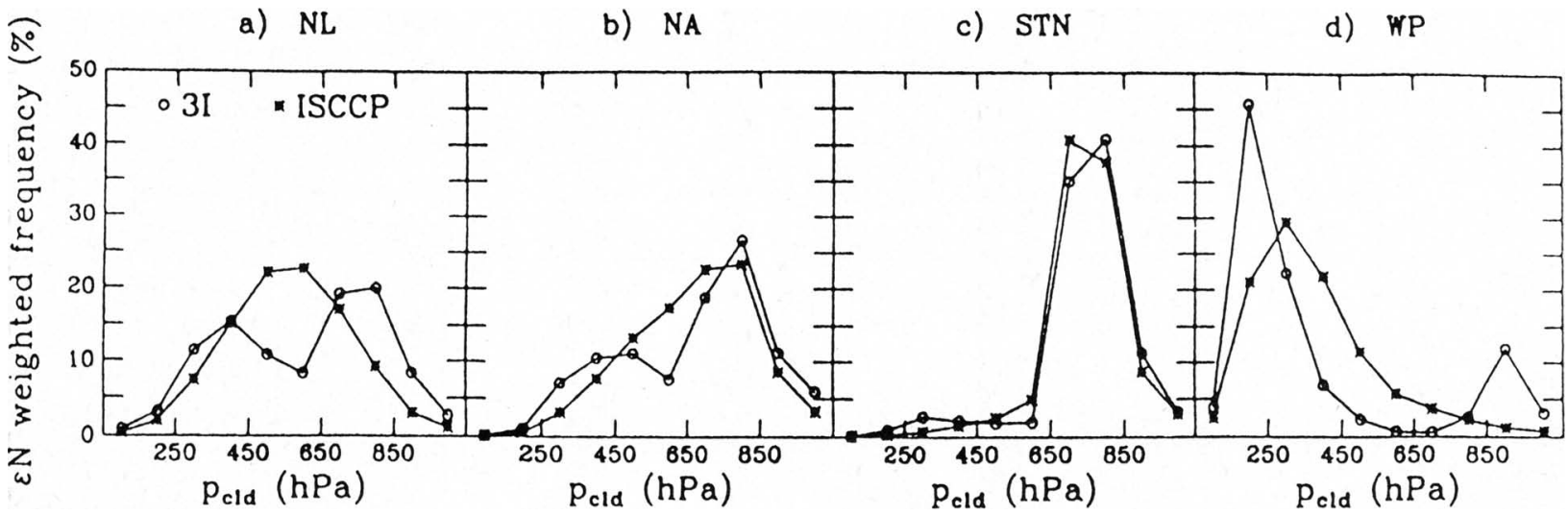

FIG. 14. Monthly mean effective cloud amount-weighted cloud-top pressure distributions as determined by $3 \mathrm{I}(\mathrm{O})$ and by ISCCP $\left(^{*}\right)$ in four different geographical regions: (a) Northern Hemisphere land, (b) North Atlantic, (c) northern stratocumulus region, and (d) tropical warm pool.

of $12.5 \mathrm{~W} \mathrm{~m}^{-2}$ (on instantaneous measurements). Focusing on clear skies, Collins and Inamdar (1995) report errors varying between 2 and $6 \mathrm{~W} \mathrm{~m}^{-2}$

Figure 16 enlarges the study with all sky comparisons for the month of January 1998: biases (3I-derived OLR minus ERBE) and standard deviations, as a function of effective cloudiness and cloud type (3I). The 

a) $\mathrm{NL}$
b) $\mathrm{NA}$
c) $\operatorname{STN}$
d) WP

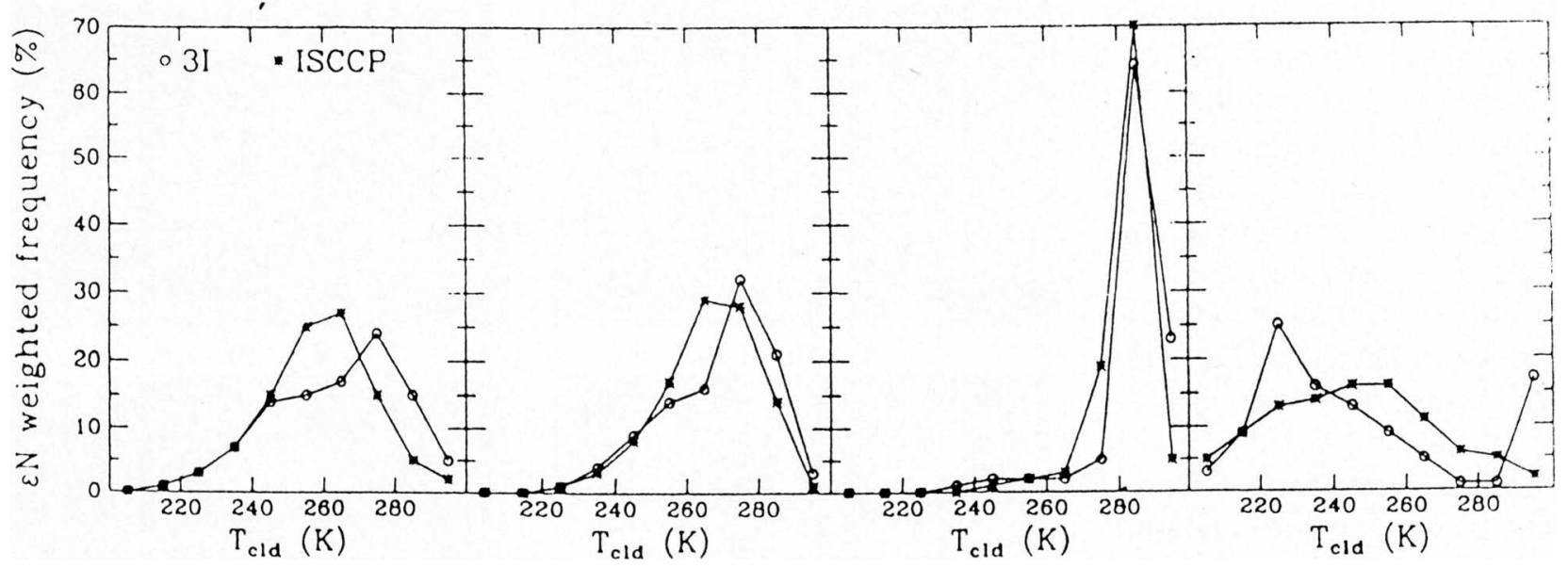

FIG. 15. Monthly mean effective cloud amount-weighted, cloud-top temperature distributions as determined by $3 \mathrm{I}(\mathrm{O})$ and by ISCCP $\left(^{*}\right.$ ) in four different geographical regions: (a) Northern Hemisphere land, (b) North Atlantic, (c) northern stratocumulus region, and (d) tropical warm pool.

standard deviation increases with increasing cloudiness up to $50 \%-60 \%$ and then decreases. Discrepancies are larger for higher clouds, with a standard deviation over $15 \mathrm{~W} \mathrm{~m}^{-2}$.

These results in cloudy skies, not as good as those for clear sky, may be related to the fact that 3I estimates effective cloud parameters. Nevertheless, defaults in the ERBE anisotropy model of the atmosphere have been pointed out in several studies (e.g., Ye and Coakley 1996) and may also explain a significant part of the differences. In particular, Stubenrauch et al. (1993) show a dependence of the ERBE flux error on cloud altitude.
TABLE 6. Statistics of the differences between 3I-derived and the ERBE determination of the outgoing longwave radiation fluxes. NOAA-10. Clear skies only.

\begin{tabular}{|c|c|c|c|c|c|c|c|}
\hline Year & Month & Orbit & Surface & $\begin{array}{c}\text { No. of } \\
\text { situations }\end{array}$ & $\begin{array}{c}\text { Bias } \\
\left(\mathbf{W} \mathbf{m}^{-2}\right)\end{array}$ & $\begin{array}{l}\text { Std dev } \\
\left(\mathbf{W} \mathbf{m}^{-2}\right)\end{array}$ & Correlation \\
\hline \multirow[t]{4}{*}{1987} & \multirow[t]{4}{*}{07} & \multirow[t]{2}{*}{ A.M. } & sea & 21957 & -1.0 & 5.8 & 0.98 \\
\hline & & & land & 26612 & 4.7 & 7.4 & 0.99 \\
\hline & & \multirow[t]{2}{*}{ P.M. } & sea & 27384 & -1.6 & 6.4 & 0.97 \\
\hline & & & land & 19556 & 3.6 & 7.5 & 0.94 \\
\hline \multirow[t]{4}{*}{1987} & \multirow[t]{4}{*}{10} & \multirow[t]{2}{*}{ A.M. } & sea & 22532 & -2.9 & 6.1 & 0.98 \\
\hline & & & land & 28415 & -1.1 & 6.3 & 0.97 \\
\hline & & \multirow[t]{2}{*}{ P.M. } & sea & 22244 & 1.1 & 6.5 & 0.97 \\
\hline & & & land & 14901 & 2.5 & 6.6 & 0.98 \\
\hline \multirow[t]{4}{*}{1988} & \multirow[t]{4}{*}{01} & \multirow[t]{2}{*}{ A.M. } & sea & 21983 & -4.1 & 7.0 & 0.99 \\
\hline & & & land & 17191 & -3.3 & 6.2 & 0.99 \\
\hline & & \multirow[t]{2}{*}{ P.M. } & sea & 33264 & -1.8 & 6.3 & 0.99 \\
\hline & & & land & 11932 & 1.3 & 6.7 & 0.99 \\
\hline \multirow[t]{4}{*}{1988} & \multirow[t]{4}{*}{04} & \multirow[t]{2}{*}{ A.M. } & sea & 31717 & -1.4 & 7.8 & 0.99 \\
\hline & & & land & 22427 & -0.0 & 7.8 & 0.97 \\
\hline & & \multirow[t]{2}{*}{ P.M. } & sea & 33997 & -0.0 & 7.5 & 0.99 \\
\hline & & & land & 13328 & 2.3 & 7.2 & 0.98 \\
\hline
\end{tabular}

\section{Conclusions}

The present paper was aimed at presenting the main characteristics of the TOVS Pathfinder "Path-B" dataset, resulting from the reanalysis of (at present) eight years of High Resolution Infrared Radiation Sounder (HIRS-2) and Microwave Sounding Unit (MSU) observations with the Improved Initialization Inversion (3I) physical-statistical retrieval algorithm. This method, designed for the interpretation of space-based observations of vertical sounders in terms of climate variables, is model independent (no influence of any forecast or climate model products), and takes great care in eliminating systematic biases that might occur, during one satellite lifetime, or from 
one satellite to another, between calculated and observed radiances. The 3I-derived climate variables are the temperature and the water vapor vertical structure, the surface temperature and type, the cloud field description (top, amount, type), and more integrated products like the longwave vertical radiative fluxes. Several auxiliary datasets (RAOBs in situ measurements, SSM/I, AVHRR or ERBE observations, ISCCP or model analyses, etc.) have been used to carry out extensive validations of 3I-derived variables. Their reported accuracies as well as their spatial resolution of $1^{\circ} \times 1^{\circ}$ (Pathfinder grid) allow for a variety of meteorological or climatological studies. If the validation of such a method at the product level (calculated values compared to observed values) is an indispensable step, its validation at the "process level" is also essential since it gives confidence in the overall coherence of the physical approach. In that sense, Claud et al. (1999), for the study of the seasonal, interannual, and zonal temperature variability of the tropical stratosphere, Chaboureau et al. (1998b) for the study of the relationship between sea surface temperature, vertical dynamics, and the vertical distribution of water vapor, or Stubenrauch et al. (1999), for a better understanding of cloud radiative effects, have contributed to the validation of the 3I Pathfinder Path-B climate archive. This archive is available from the Goddard Space Flight Center Distributed Active Archive Center and from the authors.

Acknowledgments. This work has been performed within the frame of the NOAA-NASA Pathfinder Programme. We are particularly happy to thank Martha Maiden, George Ohring, and Jim Dodge for very fruitful meetings and discussions. This work is based upon the processing of level 1-B TOVS data: we would like to warmly thank Roy Jenne and Dennis Joseph from NCAR, and Peter Topoly and Alex Kidd from NOAA/NESDIS for making these data available to us. The authors wish to acknowledge the Distributed Active Archive Center (DAAC) at the NASA/Goddard Space Flight Center for providing the level 1-B TOVS data on a suitable medium to LMD, and for providing archive and distribution support for the TOVS Pathfinder Path B data products: thanks are due to George Serafino for his invaluable assistance.

Many thanks are due to Ellen Brown and Cecil Paris from NOAA/NESDIS for making the satellite-radiosonde collocation files available to us. We are grateful to K. Petzoldt (Stratospheric Group of Free University of Berlin) for providing analyzed stratospheric temperatures. This work has been supported by CNRS, CNES, and by grants from the Commission of the European Community. For the processing of the TOVS data and for the archiving of the level 1-B and of the generated products, we have benefited from the large facilities of IDRIS, the computer center of CNRS. From the very beginning, this work has received help from several students, researchers, system engineers; among them we would like to thank Patrick Bouster, Serge Dardaillon, Dao
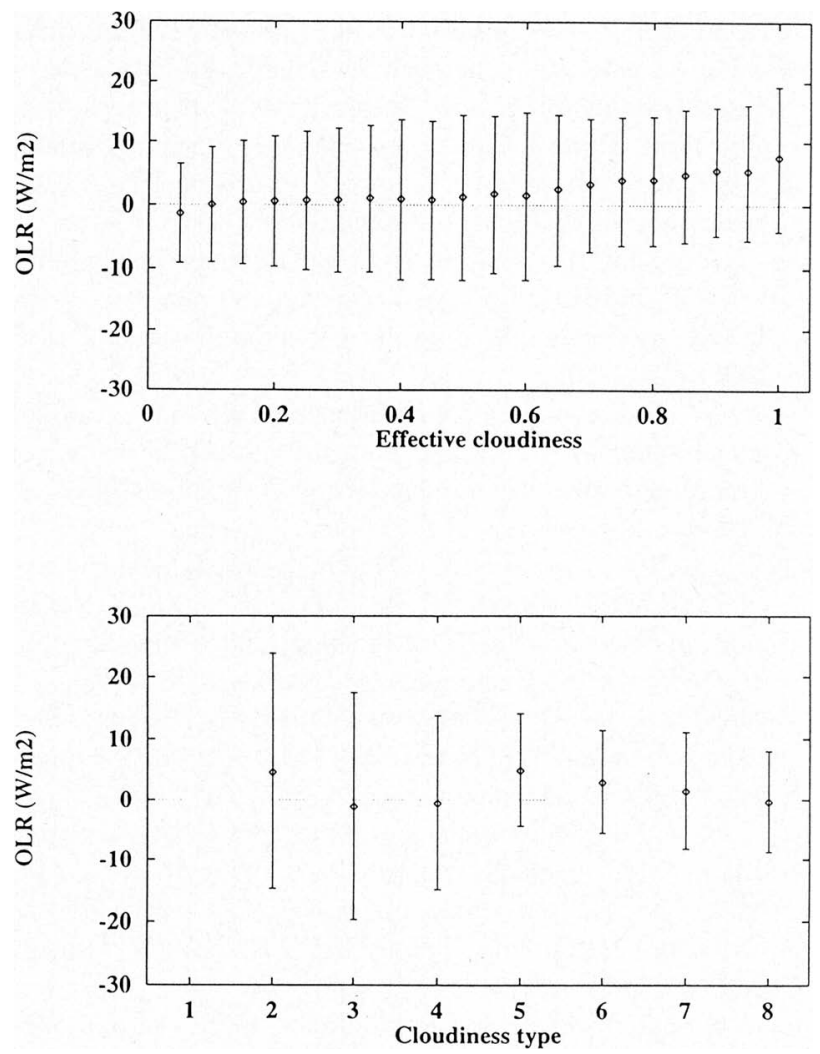

FIG. 16. Differences between the outgoing longwave flux derived from 3I and estimated by ERBE as a function of effective cloudiness (top) and cloud type (bottom): cumulonimbus (1); cirrus (2); thin cirrus (3); altostratus (4); altocumulus (5); stratus (6); cumulus (7); and clear sky (8). NOAA-10, January 1988. Vertical bars: \pm 1 standard deviation. Units are $\mathrm{W} \mathrm{m}^{-2}$.

Kasysavanh, Laurent Crepeau, Patrick Brockman, Bernard Bonnet, and Gilles Lefevre.

\section{References}

Achard, V., 1991: Trois problèmes clés de l'analyse 3D de la structure thermodynamique de l'atmosphère par satellite. Thèse de doctorat, Université Paris 7, 168 pp. [Available from Laboratoire de Météorologie Dynamique, Ecole Polytechnique, 91128 Palaiseau, France.]

Aires, F., A. Chédin, and J.-P. Nadal, 1998: Independent component analysis of geophysical time series: Application to the study of the tropical sea surface temperature. J. Geophys. Res., submitted.

Armante, R., L. Crepeau, N. A. Scott, and A. Chédin, 1998: Corrections for spurious trends in the 3I reanalysis of TOVS data. Proc. Ninth AMS Conf. on Satellite Meteorology and Oceanography, Paris, France, Amer. Meteor. Soc., 718-721.

Bauer, P., and P. Schluessel, 1993: Rainfall, total water, ice water and water vapor over sea polarized microwave simulations and Special Sensor Microwave/Imager data. J. Geophys. Res., 98, $20737-20759$. 
Chaboureau, J. P., 1997: Restitution de la structure verticale de la vapeur d'eau atmosphérique à l'échelle globale à partir d'observations satellitaires. Implications pour la sensibilité climatique. Thèse de Ecole Polytechnique, 192 pp. [Available from Laboratoire de Météorologie Dynamique, Ecole Polytechnique, 91128 Palaiseau, France.]

— A. Chédin, and N. A. Scott, 1998a: Remote sensing of the vertical distribution of atmospheric water vapor from the TOVS observations. Method and validation. J. Geophys. Res., 103, 8743-8752.

,-- , and $-1998 \mathrm{~b}$ : Relationship between sea surface temperature, vertical dynamics and the vertical distribution of atmospheric water vapor inferred from TOVS observations. $J$. Geophys. Res., 103, 23 173-23 180.

Chédin, A., 1988: The 3I retrieval method: Recent local and global applications. Proc. ECMWF Workshop on Data Assimilation and Use of Satellite Data, Reading, United Kingdom, European Centre for Medium-Range Forecasts, 181-214.

- , and N. A. Scott, 1984: Improved Initialization Inversion Procedure. First Int. TOVS Study Conf. Proc., Igls, Austria, International Radiation Commission, 14-79.

$\longrightarrow$, and -1985 : Initialization of the radiative transfer equation inversion problem from a pattern recognition type approach. Advances in Remote Sensing Retrieval Methods, Application to the Satellites of the TIROS-N Series, A. Deepak, Ed., Academic Press, 495-515.

,-- C. Wahiche, and P. Moulinier, 1985: The improved initialization inversion method: A high resolution physical method for temperature retrievals from satellites of the TIROS$N$ series. J. Climate Appl. Meteor., 24, 128-143.

,,-- E. Andersson, and J. F. Flobert, 1989: Recent developments and results of the 3 I algorithm. Proc. ECMWF/ EUMETSAT Workshop on Use of Satellite Data in Operational Numerical Weather Prediction in the Years 1989-1993, Reading, United Kingdom, European Centre for Medium-Range Forecasts, 105-126.

- - —, C. Claud, B. Bonnet, J. Escobar-Munoz, S. Dardaillon, F. Cheruy, and N. Husson, 1994: Global scale observation of the Earth for climate studies. Adv. Space Research, 14, 155-159.

Cheruy, F., F. Chevallier, J.-J. Morcrette, N. A. Scott, and A. Chédin, 1996: Une méthode utilisant les techniques neuronales pour le calcul rapide de la distribution verticale du bilan radiatif thermique terrestre. C. R. Acad. Sci. Paris, 322, 665-672.

Chevallier, F., F. Cheruy, N. A. Scott, and A. Chédin, 1998: A neural network approach for a fast and accurate computation of longwave radiative budget. J. Appl. Meteor., 37, 1385-1397.

Claud, C., N. A. Scott, and A. Chédin, 1999: Seasonal, interannual, and zonal temperature variability of the tropical stratosphere based on TOVS satellite data: 1987-1991. J. Climate, 12, 540-550.

Collins, W. D., and A. Inamdar, 1995: Validation of clear-sky fluxes for tropical oceans from the Earth Radiation Budget Experiment. J. Climate, 8, 569-578.

Elliott, W. P., and D. J. Gaffen, 1991: On the utility of radiosonde humidity archives for climate studies. Bull. Amer. Meteor. Soc., 72, 1507-1520.

Escobar-Munoz, J., A. Chédin, F. Cheruy, and N. A. Scott, 1993: Réseaux de neurones multi-couches pour la restitution de vari- ables thermodynamiques atmosphériques à l'aide de sondeurs verticaux satellitaires. C.R.A.S., 317, Série II, 911-918.

Francis, J., 1994: Improvements to TOVS retrievals over sea ice and applications to estimating Arctic energy fluxes. $J$. Geophys. Res., 99 (D5), 10 395-10 408.

Heinemann, G., S. Noël, A. Chédin, N. A. Scott, and C. Claud, 1994: Sensitivity studies of TOVS retrievals with 3I and ITPP retrieval algorithms: Application to the resolution of mesoscale phenomena in Antarctic. Meteor. Atmos. Phys., 95, 87-100.

Jin, Y., and W. B. Rossow, 1997: Detection of cirrus overlapping low-level clouds. J. Geophys. Res., 102, 1727-1737.

Kopken, K., G. Heinemann, A. Chédin, C. Claud, N. A. Scott, 1995: Assessment of the quality of TOVS-retrievals obtained with the 3I-algorithm for antarctic conditions. J. Geophys. Res., 100, 5143-5158.

Krishnamurti, T. N., H. S. Bedi, and M. Subramanian, 1989: The summer monsoon of 1987. J. Climate, 2, 321-340.

Morcrette, J. J., 1991: Radiation and cloud radiative properties in the European Centre for Medium Range Weather Forecasts Forecasting System. J. Geophys. Res., 96 (D5), 9121-9132.

Pawson, S., and B. Naujokat, 1997: Trends in daily wintertime temperatures in the northern stratosphere. Geophys. Res. Lett., 24, 575-578.

Rieu, H., J. Escobar-Munoz, N. A. Scott, and A. Chédin, 1996: SSM/T forward modelling using neural networks. J. Quant. Spectrosc. Radiat. Transfer, 56, 821-833.

Rossow, W. B., A. W. Walker, D. Beuschel, and M. Roiter, 1996: International Satellite Cloud Climatology Project (ISCCP): Description of new cloud datasets. World Climate Research Programme Rep. WMO/TD 737, 115 pp.

Rumelhart, D. E., G. E. Hinton, and R. J. Williams, 1986: Learning internal representation by error propagation. Parallel Distributed Processing: Explorations in the Macrostructure of Cognition, D. Rumelhart and J. McClelland, Eds., The MIT Press, 318-362.

Scott, N. A., and A. Chédin, 1981: A fast line-by-line method for atmospheric absorption computations: the " $4 \mathrm{~A}$ " Automatized Atmospheric Absorption Atlas. J. Appl. Meteor., 20, 801-812.

Smith, W. L., 1967: An iterative method for deducing tropospheric temperature and moisture from satellite radiation measuring. Mon. Wea. Rev., 95, 363-639.

—- H. M. Woolf, C. M. Hayden, D. Q. Wark, and L. M. McMillin, 1979: The TIROS-N operational vertical sounder. Bull. Amer. Meteor. Soc., 60, 1177-1187.

Stubenrauch, C. J., 1993: Collocation of AVHRR, ERBE and HIRS/MSU data. LMD Internal Note, 9 pp. [Available from Laboratoire de Météorologie Dynamique, Ecole Polytechnique, 91128 Palaiseau, France.]

_ longwave anisotropy emission factors from combined broadand narrowband radiance measurements. J. Appl. Meteor., 32, 848-856.

- W. B. Rossow, F. Chéruy, N. A. Scott, and A. Chédin, 1999a: Clouds as seen by satellite sounders (3I) and imagers (ISCCP). Part I: Evaluation of cloud parameters. J. Climate, 12, 2189-2213.

—, A. Chédin, R. Armante, and N. A. Scott, 1999b: Clouds as seen by satellite sounders (3I) and imagers (ISCCP). Part II: A new approach for cloud parameter determination in the $3 \mathrm{I}$ algorithms. J. Climate, 12, 2214-2223. 
W. B. Rossow, N. A. Scott, and A. Chédin, 1999c: Clouds as seen by satellite sounders (3I) and imagers (ISCCP). Part III: Combining 3I cloud parameters and ISCCP for better understanding of cloud radiative effects. J. Climate, in press.

Susskind, J., P. Piraino, L. Rokke, L. Iredell, and A. Mehta, 1997: Characteristics of the TOVS Pathfinder Path-A Dataset. Bull. Amer. Meteor. Soc., 78, 1449-1472.

Uddstrom, M. J., and L. McMillin, 1993: A collocation archive of radiosonde and satellite data: 1979 to 1993 . NOAA Tech. Memo, 54 pp. [Available from NOAA/NESDIS, Washington, DC 20233.]

Vasquez, J., K. Perry, and K. Kilpatrick, 1998: NOAA/NASA AVHRR Oceans Pathfinder sea surface temperature data set. User's reference manual, version 4.0. JPL Publication D14070.

Wahiche, C., N. A. Scott, and A. Chédin, 1986: Cloud detection and cloud parameters retrieval from the satellites of the TIROS$N$ series. Ann. Geophys., 4 (B), 207-222.
Waren, S. G., C. J. Hahn, J. London, R. M. Chervin, and R. L. Jenne, 1986: Global distribution of total cloud cover and cloud type amount over land. NCAR Tech. Note NCAR/TN273+STR, 29 pp.

Wielicki, B. A., R. D. Cess, M. D. King, D. A. Randall, and E. F. Harrison, 1995: Mission to planet Earth: Role of clouds and radiation in climate. Bull. Amer. Meteor. Soc., 76, 21252153.

Wylie, D. P., and W. P. Menzel, 1999: Eight years of high cloud statistics using HIRS. J. Climate, 12, 170-184.

Ye, Q., and J. A. Coakley, 1996: Biases in Earth radiation budget observations. 1. Effects of scanner spatial resolution on the observed anisotropy. J. Geophys. Res., 101, 21 243-21 252.

Zhong, W., and J. D. Haigh, 1995: Improved broadband emissivity parameterization for water vapor cooling rate calculations. J. Atmos. Sci., 52, 124-138.
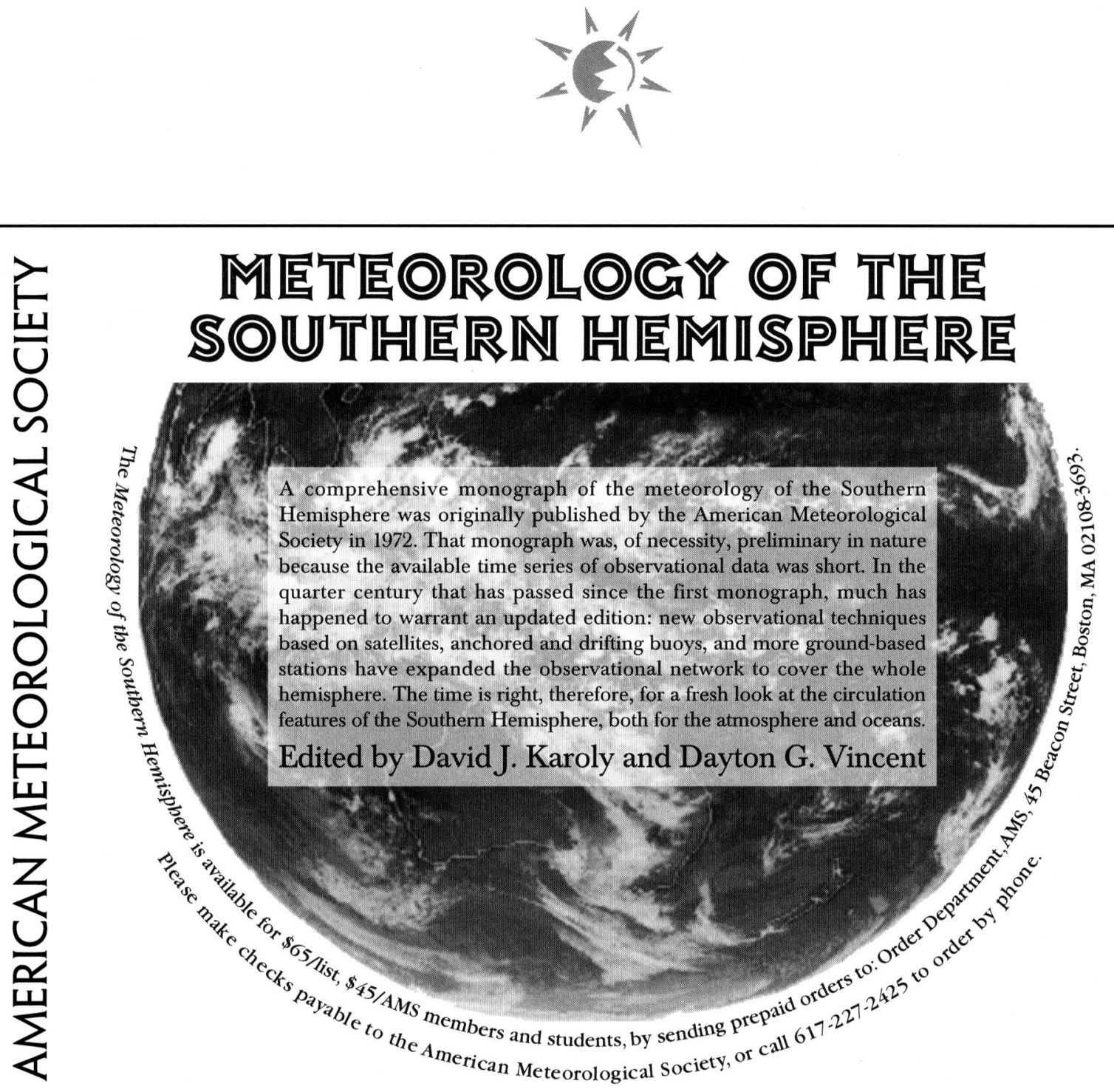
Mid-Latitude Weather Systems is the first text to make extensive use of conventional weather charts and equations to fully illustrate the behavior and evolution of weather patterns. With the use of well-documented case studies,

Pennsylvania State University Professor of Meteorology Toby Carlson has achieved a unique presentation of selected concepts, which facilitate a clear interpretation of this active and challenging area of study.

Presenting a fusion between the mathematical and descriptive fields of meteorology and integrated coverage of synoptic and dynamic approaches, Mid-Latitude

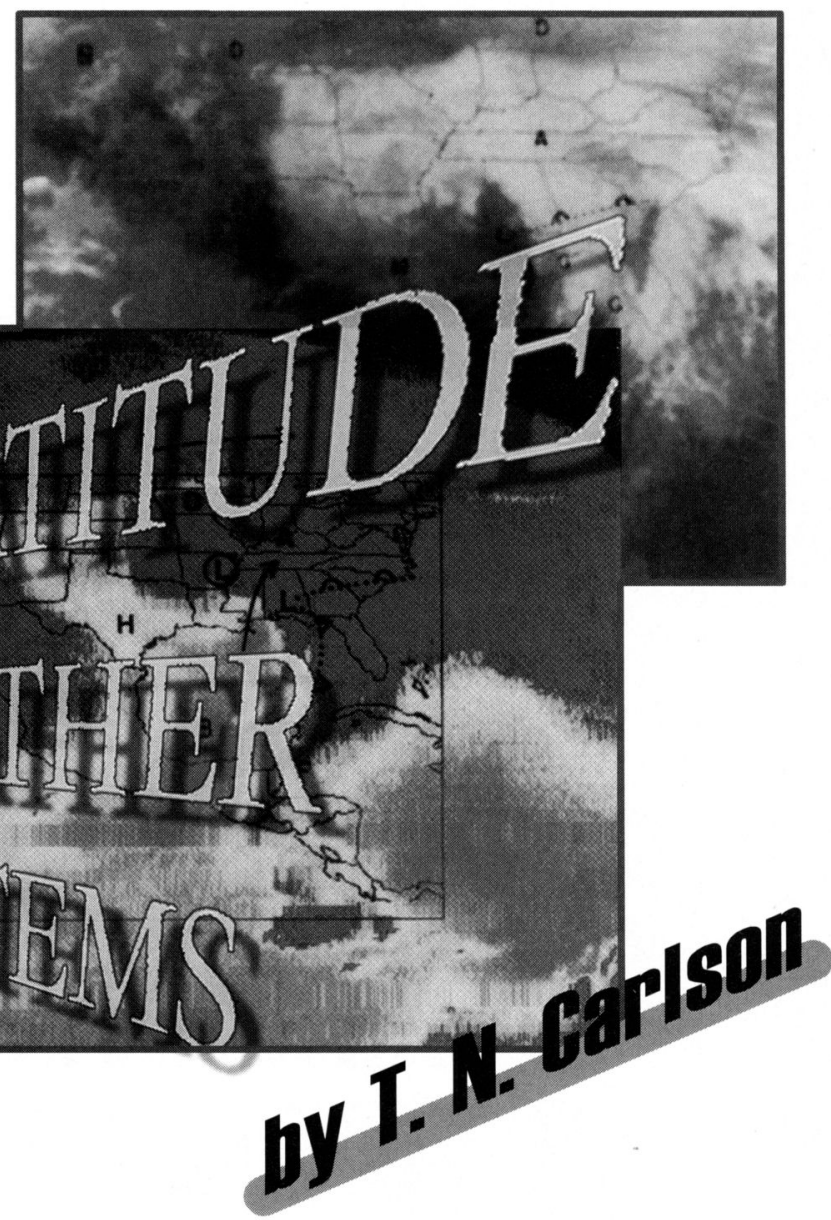
Weather Systems provides students with an invaluable course text and reference source to gain an unclouded appreciation of the underlying processes and behavior of mid-latitude weather patterns.

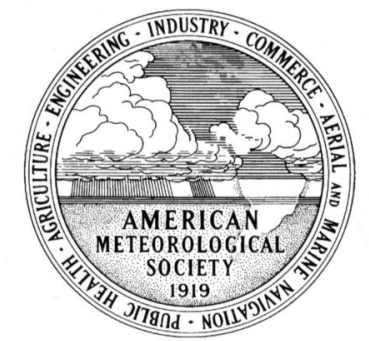

A publication of the American Meteorological Society
Mid-Latitude Weather Systems is available for $\$ 42 /$ list, \$32/AMS members, or $\$ 22 /$ student members, by sending prepaid orders to: Order Department, AMS, 45 Beacon Street, Boston, MA 02108-3693. Please make checks payable to the American Meteorological Society, or call 617-2272425 to order by phone (Mastercard, VISA, and American Express accepted). 